\title{
3-D water vapor field in the atmospheric boundary layer observed with scanning differential absorption lidar
}

\author{
Florian Späth, Andreas Behrendt, Shravan Kumar Muppa, Simon Metzendorf, Andrea Riede, and Volker Wulfmeyer \\ University of Hohenheim, Institute of Physics and Meteorology, Garbenstr. 30, 70599 Stuttgart, Germany \\ Correspondence to: Florian Späth (f.spaeth@uni-hohenheim.de)
}

Received: 15 December 2015 - Published in Atmos. Meas. Tech. Discuss.: 18 January 2016

Revised: 23 March 2016 - Accepted: 24 March 2016 - Published: 18 April 2016

\begin{abstract}
High-resolution three-dimensional (3-D) water vapor data of the atmospheric boundary layer (ABL) are required to improve our understanding of land-atmosphere exchange processes. For this purpose, the scanning differential absorption lidar (DIAL) of the University of Hohenheim (UHOH) was developed as well as new analysis tools and visualization methods. The instrument determines 3-D fields of the atmospheric water vapor number density with a temporal resolution of a few seconds and a spatial resolution of up to a few tens of meters. We present three case studies from two field campaigns. In spring 2013, the UHOH DIAL was operated within the scope of the $\mathrm{HD}(\mathrm{CP})^{2}$ Observational Prototype Experiment (HOPE) in western Germany. $\mathrm{HD}(\mathrm{CP})^{2}$ stands for High Definition of Clouds and Precipitation for advancing Climate Prediction and is a German research initiative. Range-height indicator (RHI) scans of the UHOH DIAL show the water vapor heterogeneity within a range of a few kilometers up to an altitude of $2 \mathrm{~km}$ and its impact on the formation of clouds at the top of the ABL. The uncertainty of the measured data was assessed for the first time by extending a technique to scanning data, which was formerly applied to vertical time series. Typically, the accuracy of the DIAL measurements is between 0.5 and $0.8 \mathrm{~g} \mathrm{~m}^{-3}$ (or $<6 \%$ ) within the ABL even during daytime. This allows for performing a RHI scan from the surface to an elevation angle of $90^{\circ}$ within $10 \mathrm{~min}$. In summer 2014, the UHOH DIAL participated in the Surface Atmosphere Boundary Layer Exchange (SABLE) campaign in southwestern Germany. Conical volume scans were made which reveal multiple water vapor layers in three dimensions. Differences in their heights in different directions can be attributed to different surface elevation. With low-elevation scans in the surface layer, the humidity profiles and gradients can be related to different land cover
\end{abstract}

such as maize, grassland, and forest as well as different surface layer stabilities.

\section{Introduction}

Water vapor (WV) is the most important greenhouse gas and plays a key role in Earth's weather and climate, from the surface to the troposphere to the stratosphere. Particularly important are exchange processes between the land surface and the atmospheric boundary layer (ABL) as well as between the $\mathrm{ABL}$ and the lower troposphere. For example, the diurnal cycles of evapotranspiration, the ABL moisture, and entrainment at the top of the ABL are the result of feedback processes in the land-atmosphere (LA) system (Seneviratne et al., 2010). However, generally the understanding of LA interaction has been based on model studies (e.g., Findell et al., 2003; Koster et al., 2006; van Heerwaarden et al., 2009; Santanello et al., 2013) and surface observations but not on suitable data sets including ABL WV fields.

Better parameterizations of land surface and turbulent transport processes in the ABL are essential for improved weather forecasts (e.g., Ek et al., 2003; Niu et al., 2011; Shin and Hong, 2011; Cohen et al., 2015) and regional climate projections (e.g., Warrach-Sagi et al., 2013; Milovac et al., 2016). These parameterizations were mainly derived by large eddy simulation (LES) models (e.g., Mellor and Yamada, 1982; Hong et al., 2006; Hong, 2007; Nakanishi and Niino, 2009; Shin and Hong, 2015) and only to a minor extent by observations. Vertical and horizontal moisture transports via mesoscale circulations and surface heterogeneities can result in convection initiation (CI) as well as the formation of clouds and precipitation (e.g., Behrendt et al., 2011; 
Corsmeier et al., 2011), which are very difficult to be observed from space (e.g., Aoshima et al., 2008). All these processes are interacting in a highly nonlinear way; therefore the three-dimensional (3-D) WV content needs to be represented very well in weather forecast models (Crook, 1996; Dierer et al., 2009), reanalyses (Bengtsson et al., 2004), and climate models (e.g., Kotlarski et al., 2014).

Models are only as good as the observations which were used for their parameterization and verification. Advanced observations of WV to study exchange, feedback, and mesoscale circulation processes require the observation of the 3-D WV field with a resolution permitting the simultaneous measurement of vertical gradients in the WV distribution in the surface layer, the mixed layer, and the entrainment layer at the top of the ABL. Only if these gradients are resolved, the corresponding transport processes can be studied and parameterized (Monin and Obukhov, 1954; Wulfmeyer et al., 2016). However, the distribution of ABL WV and its evolution in time is neither fully understood nor sufficiently observed. In consequence, it is not adequately reproduced in weather and climate forecasting models. A detailed overview about these processes and the requirements set to suitable observing systems is given by Wulfmeyer et al. (2015).

For WV measurements passive and active remote sensing instruments as well as in situ sensors are available. In situ sensors only deliver data from one location at one time; thus, remote sensing instruments are preferred for studying the vertical and horizontal WV structure in the ABL. However, many remote sensing systems only provide integrated WV (IWV) data which give no spatial information. Passive instruments like infrared (IR) spectrometers or microwave radiometers (MWRs) are able to retrieve WV profiles based on a first guess with temporal resolutions of 5-10 min. Their vertical range resolutions are $100 \mathrm{~m}$ for IR spectrometers or several $100 \mathrm{~m}$ for MWRs at the land surface and approximately $800 \mathrm{~m}$ for IR spectrometers and $2000 \mathrm{~m}$ for MWRs at the top of the ABL (Löhnert et al., 2009; Blumberg et al., 2015; Wulfmeyer et al., 2015). Due to these coarse vertical resolutions, fine structures and gradients cannot be resolved. A combination of several systems may be used to determine horizontal structures with the tomography technique. This was simulated for scanning MWRs (Steinke et al., 2014) but the vertical resolution still remains low due to the coarse resolution of the initial signals and inaccurate knowledge of initial fields. To analyze the aforementioned processes in the ABL, like LA feedback or CI, higher WV resolutions in time and space are needed. The corresponding requirements are summarized in Table 1 in Wulfmeyer et al. (2015).

For WV profiling with lidar, the Raman technique (e.g., Melfi et al., 1969; Whiteman et al., 1992; Behrendt et al., 2002; Hammann et al., 2015, Wulfmeyer et al., 2010) or the WV differential absorption lidar (WVDIAL) technique (Schotland, 1966; Browell et al., 1979; Bösenberg, 1998; Wulfmeyer and Bösenberg, 1998) can be applied. An overview of the performance of these techniques is given in Behrendt et al. (2007) and Bhawar et al. (2011). It was shown that WVDIAL has a better spatial/temporal resolution in the lower troposphere than WV Raman lidar (WVRL) during daytime (Wulfmeyer and Bösenberg, 1998). The WVDIAL technique uses two elastic backscatter signals at wavelengths with high and low absorption of WV. In contrast to WVRL, the WVDIAL technique is self-calibrating and needs no further information than the absorption cross section at the wavelengths used (Browell et al., 1979). Due to the elastic backscatter signals, the signal-to-noise ratio (SNR) is much higher for the detected signals than using inelastic Raman scattered signals. This also helps to reach a larger range during daytime and allows integration times to be kept short. The horizontal variations of the moisture fields can be detected with scanning lidar. Scanning WVRL measurements were used, for example, to observe the WV structures in the ABL (Goldsmith et al., 1998; Eichinger et al., 1999; Whiteman et al., 2006; Froidevaux et al., 2013; Matsuda, 2013) or to estimate latent heat fluxes at the surface (Eichinger et al., 2000). However, the SNR is still limited during daytime (Turner at al., 2002), making high-resolution scans under daylight conditions more difficult than with WVDIAL; and 3-D measurements of WVRL have not been demonstrated yet.

Therefore, we focused on the WVDIAL technique and developed a scanning system permitting high-resolution scans of the WV field even during daytime. The University of Hohenheim (UHOH) WVDIAL is a ground-based mobile instrument which has already demonstrated vertical measurements in the ABL with high resolution and accuracy (Bhawar et al., 2011; Muppa et al., 2016; Wulfmeyer et al., 2016). Here, we present different types of scanning measurements of this system and discuss the measurement uncertainties. Particularly, we demonstrate the measurement of a 3-D water vapor field, which to our knowledge was achieved for the first time with a lidar.

We focus on three different scan strategies.

1. With range-height indicator (RHI) scanning measurements, the vertical WV structure over a certain horizontal range can be observed. We present a new technique to determine the corresponding 2-D error field and discuss the measurement performance in this configuration. This is essential to find the best compromise between scan speed and temporal and range resolution in order to detect the fine structure of the WV field with high confidence.

2. Conical scans can be performed to study the humidity variations from the mixed layer throughout the top of the ABL. Combining several of such scans with different elevations yields a 3-D image of the ABL moisture field. We discuss a corresponding first measurement and derive the error statistics in order to characterize fine structures in the WV field. 

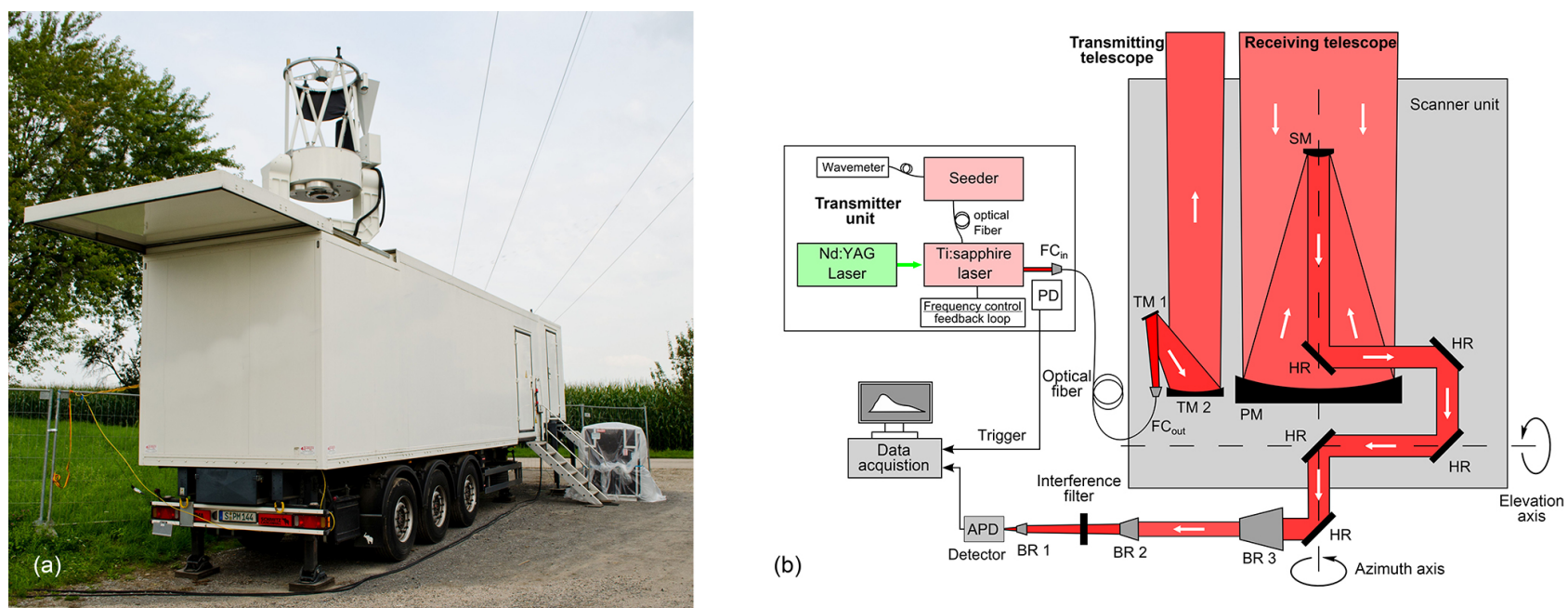

Figure 1. (a) Photograph of the DIAL system in the field during the SABLE experiment. (b) Setup of the UHOH DIAL system with transmitter unit, the scanner unit with transmitting and receiving telescope, and the detection path with data acquisition. TM - transmitting telescope mirror, PM - primary mirror, SM - secondary mirror, HR - high-reflection mirror, BR - beam reducer, APD - avalanche photo diode, $\mathrm{PD}$ - photo diode, FC - fiber coupler.

3. Low-elevation scans close to the surface can be used to study LA feedback processes. The applied elevation angle range was 0 to $12^{\circ}$ and because of overlap effects, the measurement range started at $300 \mathrm{~m}$. Also here, the error statistics are derived in order to investigate how accurately the small-scale variability of the ABL WV field from the surface to the mixed layer can be derived.

The UHOH DIAL system is introduced in Sect. 2. The DIAL technique and the data analysis procedure are presented in Sect. 3. The three different scanning strategies are discussed in Sects. 4-6. Finally, results are summarized and an outlook is given in Sect. 7.

\section{University of Hohenheim water vapor DIAL system}

The laser transmitter of the UHOH DIAL (Fig. 1) is based on a Ti:sapphire ring laser (Schiller, 2009; Wagner et al., 2011, 2013) which is end-pumped with the frequency-doubled radiation of a pulsed diode-pumped Nd:YAG laser (Ostermeyer et al., 2005). Frequency control is realized with the injection seeding technique (Barnes et al., 1993a, b) in combination with a resonance frequency control (e.g., Wulfmeyer and Bösenberg, 1996). For the measurements described in this paper, the previous transmitter configuration (Wagner et al., 2013) was modified by the following aspects. The pump laser has undergone a full redesign and consists now of an unidirectional ring oscillator in triangle configuration. The resonator of the Ti:sapphire laser has also been changed. Now, four resonator mirrors form a dynamically stable ring resonator in bow-tie configuration (Metzendorf et al., 2012). A new seed laser system with two frequencystabilized distributed feedback (DFB) laser diodes as in- jection seeders (Späth et al., 2013) was operated for the first time as part of the transmitter during the High Definition of Clouds and Precipitation for advancing Climate Prediction $\left(\mathrm{HD}(\mathrm{CP})^{2}\right)$ Observational Prototype Experiment (HOPE). For the Surface Atmosphere Boundary Layer Exchange (SABLE) campaign, the online DFB laser was later replaced by an external cavity diode laser (ECDL) with excellent passive frequency stability (Metzendorf et al., 2015) combined with the Drever-Hall-Wulfmeyer frequency control technique for pulsed, injection-seeded laser (US patent no. 6,633,596, Wulfmeyer et al., 2000).

The UHOH DIAL has two configurations for transmitting the laser pulses to the atmosphere and receiving the backscattered lidar signals: one for vertical pointing measurements and one for scanning measurements. In the scanning configuration (the only one shown in Fig. 1b), the laser pulses are coupled into an optical fiber and transmitted to the atmosphere via a $20 \mathrm{~cm}$ telescope. The laser output power is currently restricted to $2 \mathrm{~W}$ in this configuration because experiments showed that this type of fiber accepts only up to this power level before being damaged. Due to losses when coupling the light into the fiber and out as well as due to the transmitting telescope optics, the power transmitted into the atmosphere is then $1.6 \mathrm{~W}$. The backscattered photons are collected with an $80 \mathrm{~cm}$ diameter telescope with a focal length of $10 \mathrm{~m}$. The transmitting and receiving telescopes are mounted together on the scanner unit using a receiver in Coudé configuration with excellent pointing stability on the detector, which allows for 3-D observations. The scanner unit can be operated with speeds between 0.1 and $6^{\circ} \mathrm{s}^{-1}$. The control software of the scanner unit offers predefined modes like range-height indicator (RHI - varying elevation angle 
Table 1. Instrument specifications of the UHOH DIAL for scanning WV measurements.

\begin{tabular}{lr}
\hline Parameter & \\
\hline Pump power $(532 \mathrm{~nm})$ & $14 \mathrm{~W}$ \\
Repetition rate & $250 \mathrm{~Hz}$ \\
Ti:sapphire output power $(820 \mathrm{~nm})$ & $2 \mathrm{~W}$ \\
Pulse energy & $8 \mathrm{~mJ}$ \\
Pulse duration & $60 \mathrm{~ns}$ \\
Frequency switching & Shot to shot on-/offline \\
& $2 \times 1$ optical fiber switch \\
Wavelength range & $817.7-819.0 \mathrm{~nm}$ \\
Output power sent into the atmosphere & $1.6 \mathrm{~W}$ \\
Transmitting telescope diameter & $20 \mathrm{~cm}$ \\
Receiving telescope diameter & $80 \mathrm{~cm}$ \\
Scan speed & $0.1-6.0^{\circ} \mathrm{s}-1$ \\
Sampling rate & $10 \mathrm{MHz}$ \\
Typical time resolutions & $1 \mathrm{~s}-1 \mathrm{~min}$ \\
Typical range resolutions & $30-300 \mathrm{~m}$ \\
\hline
\end{tabular}

and fixed azimuth angle) scans and conical scans (varying azimuth angle and fixed elevation angle) as well as different types of volume scans. The signals are detected by an avalanche photodiode (APD) in combination with a highly linear and low-noise transimpedance receiver package from the German Aerospace Center DLR. Further details of the transmitter-receiver unit are presented in Riede et al. (2012).

The 14 bit data acquisition system (transient recorder MI.4032, Spectrum GmbH, Germany) records the atmospheric backscatter signals with typically $10 \mathrm{MHz}$ sampling rate, resulting in a range resolution of the raw signals of $15 \mathrm{~m}$. We store the backscatter signals of each laser shot, which gives us maximum flexibility later when analyzing the data. Together with the lidar signals, elevation and azimuth angles of the telescope are recorded with each pulse. For the WV calculation, the raw data are typically averaged over $1 \mathrm{~s}$ to $1 \mathrm{~min}$ in time for the online and offline data. Range averaging is applied within the WV derivation (so-called SavitzkyGolay derivation). The system specifications of the UHOH DIAL are summarized in Table 1.

In recent years, the performance of the UHOH DIAL system was investigated within several intercomparison campaigns. Bhawar et al. (2011) performed an extensive comparison study between the UHOH DIAL and six other WV lidar systems during the Convective and Orographically-induced Precipitation Study (COPS) in 2007 (Wulfmeyer et al., 2011; Behrendt et al., 2013). They found a bias of only $-1.43 \%$ for the UHOH DIAL relative to the mean of all measurements. In 2013, in Hohenheim, Stuttgart (Germany), a further comparison study with Vaisala RS-92 radiosondes was performed and resulted in a mean bias of $-1.0 \% \pm 2.6 \%$ (Späth et al., 2014). Following the method of Lenschow et al. (2000) and Wulfmeyer et al. (2016), an analysis of the autocovariance function of the WV time series at each height is used to distinguish between instrumental noise and atmospheric vari- ances. This technique yielded a noise error of $<5 \%$ up to $2 \mathrm{~km}$ using a time resolution of 1-10 s (Muppa et al., 2016). Here, we demonstrate for the first time how this technique can be modified and adapted to perform error analysis of 2$\mathrm{D}$ to 3-D scanning measurements.

\section{Data processing and derivation of $\mathrm{WV}$ profiles}

\subsection{DIAL methodology}

With the DIAL technique the number density of water vapor (or other trace gases like ozone, methane, etc.) can be measured directly with two backscatter lidar signals. One signal is tuned to a wavelength with strong absorption of WV $\left(P_{\text {on }}(r)\right.$ : online signal $)$ and the other signal to a wavelength with weak absorption $\left(P_{\text {off }}(r)\right.$ : offline signal). The range $r$ is measured from the lidar system to the scattering volume along the line of sight. The return signals $P(r)$ for each wavelength can be described with the lidar equation of elastic backscattering as (Wulfmeyer et al., 2015)

$$
\begin{aligned}
P_{\nu_{0}}(r)= & P_{0} \eta \frac{c \Delta t}{2} \frac{A_{\text {tel }}}{r^{2}} O(r) \Gamma_{\text {air }, v_{0}}^{2}(r) \\
& \times\left\{\beta_{\mathrm{par}, v_{0}}(r) \int_{-\infty}^{+\infty} S_{\mathrm{L}}\left(v-v_{0}\right) \Gamma_{\mathrm{WV}}^{2}(v, r) F_{\mathrm{R}}(v, r) \mathrm{d} v\right. \\
& +\beta_{\mathrm{mol}, v_{0}}(r) \int_{-\infty}^{+\infty}\left[\left[S_{\mathrm{L}}\left(v-v_{0}\right) \Gamma_{\mathrm{WV}}(v, r)\right]\right. \\
& \left.\times \mathrm{DB}(v, r)] \Gamma_{\mathrm{WV}}(v, r) F_{\mathrm{R}}(v, r) \mathrm{d} v\right\}+P_{\mathrm{B}}
\end{aligned}
$$

with the transmitted intensity $P_{0}$ at the laser frequency $v_{0}$, the system efficiency $\eta$, the speed of light $c$, the sampling resolution of the system $\Delta t$, the telescope area $A_{\text {tel }}$, the overlap function $O(r)$, the transmission of the atmosphere $\Gamma(r)$ as

$$
\begin{aligned}
\Gamma_{v}(r)= & \Gamma_{\text {air }, v}(r) \Gamma_{\mathrm{WV}}(v, r) \\
= & \exp \left\{-\int_{0}^{r}\left[\alpha_{\mathrm{par}, v}\left(r^{\prime}\right)+\alpha_{\mathrm{mol}, v}\left(r^{\prime}\right)\right] \mathrm{d} r^{\prime}\right\} \\
& \times \exp \left\{-\int_{0}^{r} \alpha_{\mathrm{WV}}\left(v, r^{\prime}\right) \mathrm{d} r^{\prime}\right\},
\end{aligned}
$$

the particle and molecular extinction coefficient $\alpha_{\mathrm{par}, v}(r)$ and $\alpha_{\mathrm{mol}, v}(r)$, which are only slightly dependent on frequency $v$, the extinction coefficient of water vapor (of the trace gas) $\alpha_{\mathrm{WV}}(\nu, r)$, the particle and molecular backscatter coefficient $\beta_{\mathrm{par}, v}(r)$ and $\beta_{\mathrm{mol}, v}(r)$, the normalized laser spectrum at the ground $S_{\mathrm{L}}$, the spectral broadening due to Dopplerbroadened Rayleigh scattering, DB, the transmission function of the receiver interference filter $F_{\mathrm{R}}$, and $P_{\mathrm{B}}$ the background signal. $\alpha_{\mathrm{WV}}$ is related to the absorption cross section 
$\sigma_{\mathrm{WV}}$ and the WV number density $N_{\mathrm{WV}}$ by

$\alpha_{\mathrm{WV}}(v, r)=N_{\mathrm{WV}}(r) \sigma_{\mathrm{WV}}(v, r)$.

Our laser is designed so that the laser spectrum can be considered a delta distribution. In this case, the derivation of the WV profile becomes independent of any laser parameters, which is called narrow-band DIAL. Furthermore, we assume that the overlap function is either the same for online and offline signals or height independent; we also consider the interference filter transmission function to be constant over the frequency range of interest and not dependent on range. Then, calculating the ratio of Eq. (1) for online and offline wavelengths, applying the relation of Eq. (3), and solving for the WV number density $N_{\mathrm{WV}}$ leads to the narrow-band DIAL equation

$N_{\mathrm{WV}}(r)=$

$\frac{1}{2\left(\sigma_{\mathrm{on}}(r)-\sigma_{\mathrm{off}}(r)\right)} \frac{\mathrm{d}}{\mathrm{d} r} \ln \left(\frac{P_{\text {off }}(r)-P_{\mathrm{B}, \text { off }}}{P_{\mathrm{on}}(r)-P_{\mathrm{B}, \mathrm{on}}}\right)$

$+\frac{1}{2\left(\sigma_{\text {on }}(r)-\sigma_{\text {off }}(r)\right)} \frac{\mathrm{d}}{\mathrm{d} r} \ln$

$\left(\frac{\beta_{\mathrm{par}, \mathrm{on}}(r)+\beta_{\mathrm{mol}, \mathrm{on}}(r) \Gamma_{\mathrm{WV}, \text { on }}^{-1}(r) \int_{-\infty}^{\infty} \Gamma_{\mathrm{WV}}(v, r) \mathrm{DB}\left(v-v_{\mathrm{on}}, r\right) \mathrm{d} v}{\beta_{\mathrm{par}, \mathrm{off}}(r)+\beta_{\mathrm{mol}, \mathrm{off}}(r)}\right)$,

where the index "on" and "off" implies that the specific variable is taken at the online or offline wavelength, respectively. Online and offline wavelengths are chosen close to each other because then the particle and molecular extinction and backscatter coefficients for online and offline wavelengths cancel when taking the ratio of the signals in Eq. (4). All system parameters which are constant with range $r$ cancel because of the derivative. Thus, for DIAL measurements no calibration is needed. Only the values of the absorption cross sections at online and offline wavelength $\sigma_{\text {on }}$ and $\sigma_{\text {off }}$ have to be known very accurately.

The second term in Eq. (4) describes the Rayleigh Doppler correction term related to the broadening effect of the laser spectrum by Rayleigh scattering. The particle backscatter coefficient can be calculated from the offline signal (Fernald et al., 1972; Fernald, 1984). Ansmann and Bösenberg (1987) showed that this correction becomes significant when strong particle backscatter gradients are present. However, they only considered that the online laser wavelength is at the peak of the water vapor absorption line.

Within the analyses presented here this effect was not critical, as confirmed not only by comparisons with radiosoundings but also with new sensitivity analyses considering a frequency agile operation of our laser transmitter (Metzendorf et al., 2015). This reduced sensitivity to the Rayleigh Doppler correction was due to two reasons. Firstly, most of the sampled air masses were located within the ABL where no large particle backscatter gradients were present. Secondly, the
Rayleigh Doppler effect is strongly reduced if the online frequency is located on the wing of the absorption line. In this case, the integral in Eq. (4) becomes approximately $\Gamma_{\mathrm{wv}, \mathrm{on}}$, so the nominator and the denominator of the term cancel - independent of the aerosol gradient. More details can be found in Späth et al. (2015). For the measurements discussed here, we selected an online frequency away from the peak absorption but still strong enough to produce sufficient differential absorption. This selection allowed us to optimize the sensitivity of the DIAL measurements in the range of interest for the moisture values present (Späth et al., 2014). Thus, the so-called Schotland approximation of the DIAL equation (Schotland, 1966, 1974)

$$
N_{\mathrm{WV}}(r)=\frac{1}{2\left(\sigma_{\mathrm{on}}(r)-\sigma_{\mathrm{off}}(r)\right)} \frac{\mathrm{d}}{\mathrm{d} r} \ln \left(\frac{P_{\mathrm{off}}(r)-P_{\mathrm{B}, \text { off }}}{P_{\mathrm{on}}(r)-P_{\mathrm{B}, \text { on }}}\right)
$$

was used for all cases presented here. With this approximation no backscatter coefficients were needed for the calculation. In the following, the derived moisture values in number density are transformed in absolute humidity $\rho$ in units of $\mathrm{g} \mathrm{m}^{-3}$.

The WV cross section $\sigma_{\mathrm{WV}}\left(\nu, T, p, N_{\mathrm{WV}}\right)$ depends on $N_{\mathrm{WV}}$ by self-broadening, temperature $T$, and air pressure $p$ at a certain frequency $v$. These dependencies have been measured very accurately in the laboratory and collected in databases, e.g., the HIgh-resolution TRANsmission molecular absorption database (HITRAN) (Rothman et al., 2013). Selecting specific absorption lines with low ground-state energy, it was shown that the dependence of the cross sections on the atmospheric temperature, pressure, and $\mathrm{WV}$ profiles is weak and that it is sufficient to assume mean hydrostatic and adiabatic conditions merely using surface values. This makes DIAL the most accurate WV remote sensing technique to date.

Suitable wavelength regions for WVDIAL were discussed over a large wavelength range by Wulfmeyer and Walther (2001a, b). Specific DIAL systems were developed, e.g., near $720 \mathrm{~nm}$ (Bruneau et al., 2001; Wulfmeyer and Bösenberg, 1998), near $820 \mathrm{~nm}$ (Ismail and Browell, 1989; Ertel, 2004; Schiller et al., 2007; Vogelmann et al., 2008; Behrendt et al., 2009; Spuler et al., 2015), near $935 \mathrm{~nm}$ (Machol et al., 2004, 2006; Wirth et al., 2009; Fix et al., 2011), and near $1480 \mathrm{~nm}$ (Petrova-Mayor et al., 2008). The UHOH DIAL operates at wavelengths near $818 \mathrm{~nm}$ because this wavelength region can be reached well with a Ti:sapphire transmitter and offers a sufficiently large range of WV absorption cross sections (Wagner et al., 2011, 2013).

\subsection{Data processing}

In case of the UHOH DIAL, the atmospheric backscatter data are recorded for each laser shot. Later, these data are averaged in time over typically $1-10 \mathrm{~s}$ and background corrected by subtracting the averaged signal between 25 and $30 \mathrm{~km}$. The absorption cross section profiles for the selected online 
and offline wavelengths are determined using profiles of temperature $T(z)$ using a surface value in combination with the temperature gradient from the US Standard Atmosphere, a hydrostatic pressure $p(z)$ also initialized with a surface value and an atmospheric mean temperature in the range of interest. An initial guess for the water vapor number density $N_{\mathrm{WV}}(z)$ is taken from the US Standard Atmosphere (NASA, 1976). We take the spectroscopic parameters of water vapor from the latest compilation of HITRAN described by Rothman et al. (2013).

The water vapor profile is then calculated according to Eq. (5) (Schotland approximation). The Savitzky-Golay (SaGo) method is applied for the derivative with respect to range $r$ (Savitzky and Golay, 1964). This method calculates the first derivative using a certain number of data points. The resulting range resolution $\Delta R$ is approximately half of the $\mathrm{SaGo}$ window length, as the weighting function is parabolic (Ehret et al., 2001). Typically our SaGo window range consists of four data points on each side of a specific range, resulting in a range resolution of $9 \times 15 \mathrm{~m} / 2 \cong 67.5 \mathrm{~m}$. The $15 \mathrm{~m}$ step size of the data points used for the derivation of the WV profile is kept. Depending on whether Eqs. (4) or (5) must be applied, either an iteration is necessary to derive the WV profiles (Eq. 4) or a direct derivation is sufficient (Eq. 5). However, in both cases the resulting solution is unique and even if an iteration must be applied to find the result it converges very quickly after one to three iterations. The whole chain of data processing is summarized in a flow chart (see Fig. 2).

\subsection{Analysis of scanning data}

Up to this step, the analysis procedure is similar for vertical and for scanning measurements. After calculating the WV of scanning measurement, the data can be plotted and used for further analysis in polar coordinates $(r, \Theta, \phi)$. Alternatively, the data can be gridded to a regular horizontally and vertically spaced grid $(x, y, z)$ (see also Fig. 2 ). We prefer gridded data because atmospheric variations are usually horizontally or vertically oriented. 3-D data sets can be analyzed by extracting slices of different orientation.

To estimate instrumental noise $\Delta \rho$ of vertical measurements, we apply the method of Lenschow et al. (2000) and Wulfmeyer et al. (2016). Here, the autocovariance function (ACF) of the humidity fluctuations for one range bin is determined. The ACF at lag 0 gives the total variance which is the sum of atmospheric variance and noise variance. The atmospheric variance can be separated from the instrumental noise by extrapolating the ACF to lag 0 . For conical scanning measurements, this approach can be used without further modification because data points of a certain range are at the same height.

For scanning measurements in RHI mode, the determination of the atmospheric variance is more complicated. When a time series with a large number of fast RHI measurements

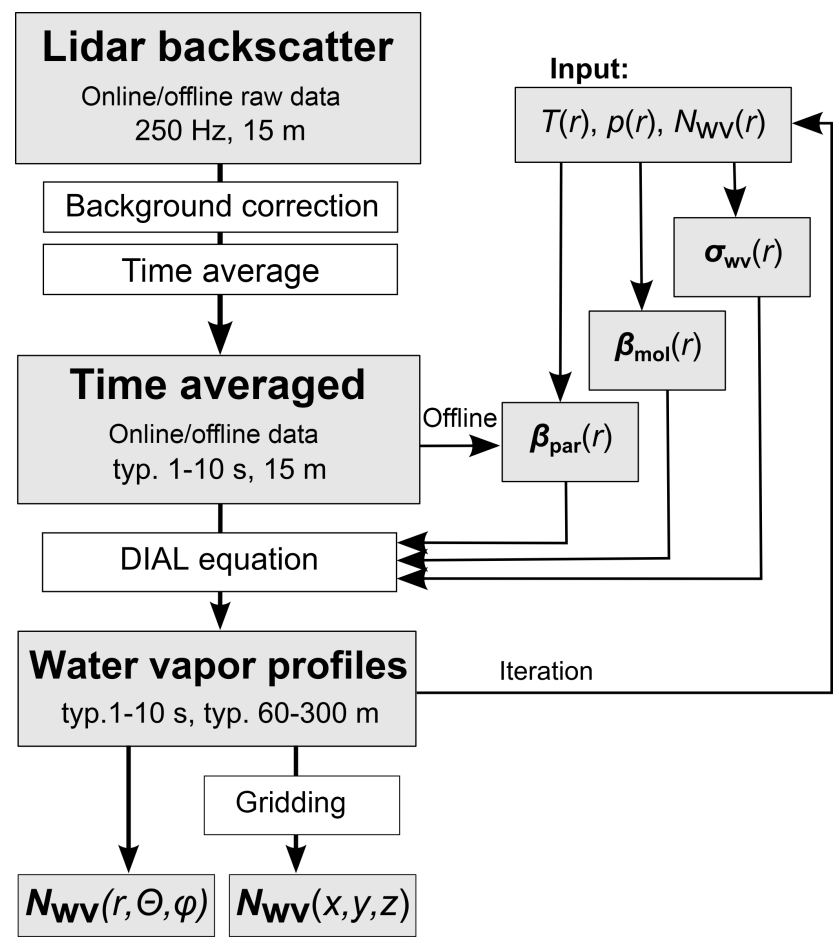

Figure 2. Flow chart of data processing. The backscatter coefficients $\beta_{\text {par }}(r)$ and $\beta_{\text {mol }}(r)$ are only used if the Rayleigh Doppler correction (Eq. 4 ) is required. For the cases presented here, we used the Schotland approximation (Eq. 5).

with small periods between consecutive scans such as tens of seconds (when scanning fast with $6^{\circ} \mathrm{s}^{-1}$ ) or a few minutes (as for the low-elevation scans with one scan per minute) is available, one can just use the time series of data at one range and elevation. However the noise within single RHI data can also be determined. In contrast to conical scans, rings of constant range cover different heights for RHI data and thus clearly different atmospheric variance values; but even more importantly, the instrumental noise within an RHI scan that covers a large part of the ABL differs for fixed range because the humidity and thus the optical depth show large differences (Wulfmeyer and Walther, 2001b). In consequence, one has to group the measured RHI data then in a more sophisticated way. In the following, we suggest such an approach.

We have tested several different concepts for grouping the data. A simple 1-D approach is to take a number of range bins from one slant profile, but as the required number of independent measurement points is about 10 , this still leads to very similar problems as discussed above when selecting measurement points of constant range. Thus, we finally decided to group the measured data set with very high resolution two-dimensionally. We calculate the noise estimation with three independent data points of three profiles giving $3 \times 3=9$ data points for each group that is analyzed. The vertical noise profile is then obtained from groups of which the central data points are at a certain horizontal distance to 


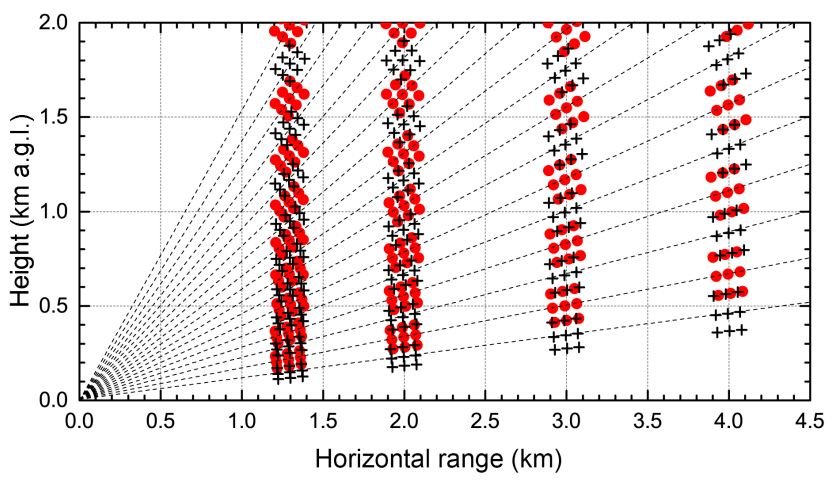

Figure 3. Spatial distribution of the grouping of the measured data used for the noise estimation for a single RHI scan. For each group of nine data points, either black pluses or red dots, the ACF is calculated. Different symbols are used for better understanding when the data points are close to each other. Dashed lines indicate each second profile.

the lidar (Fig. 3). The data set used for the error estimate has the very high resolution over the entire distance range.

When using RHI data sets with very high spatial resolution (in range and elevation), the instrumental noise is much larger than the atmospheric variance. Thus the sequence of the nine data points of each group used for the ACF analysis becomes irrelevant and one can just use lag 0 as the upper limit for the instrumental noise estimation. Finally, the resulting noise values are scaled to the temporal and spatial resolution of the averaged and gridded data according to Ismail and Browell (1989):

$$
\frac{\Delta \rho}{\rho} \propto(\Delta t)^{-0.5}(\Delta r)^{-1.5} .
$$

In doing so, for the temporal resolution of RHI scans, the scaling results in different angle resolutions.

In the following, we present several examples of 2-D and 3-D scans of the WV fields, analyze the results, and apply our new tools for error analyses.

\section{Range-height indicator scans to investigate 2-D turbulence and clouds in the $\mathrm{ABL}$}

\subsection{Instrumental setup}

To capture the horizontal and vertical WV field and its relation to 2-D ABL turbulence statistics and cloud formation, RHI scanning measurements are preferable. With vertical measurements only observations in the so-called Eulerian specification are possible which means that the atmosphere is observed while advecting through the lidar beam. Here, temporal and spatial changes of the measured data are entangled. With RHI scans, this is not the case (or at least much less); therefore both temporal and spatial differences of the moisture field in the ABL can be studied.
The UHOH DIAL was operated in RHI mode within the $\mathrm{HD}(\mathrm{CP})^{2}$ Observation Prototype Experiment (HOPE) near Forschungszentrum Jülich, in western Germany (see http: //www.hdcp2.eu/Campaign-HOPE.2306.0.html). The aim of the experiment was to produce a data set of atmospheric measurements for the investigation of land-atmosphere interaction, cloud formation, aerosol-cloud microphysics as well as weather and climate model evaluation at the $100 \mathrm{~m}$ scale. For HOPE, three supersites were set up in a triangular configuration with distances of about $4 \mathrm{~km}$ between each other. All these sites were equipped with in situ and remote sensing instruments to measure atmospheric parameters. With the different instruments, the temporal and spatial heterogeneity of the convective boundary layer (CBL) was investigated concerning WV, temperature, and wind fields as well as the distribution of aerosol particles and clouds. The UHOH DIAL was located at the HOPE supersite near Hambach (50 $53^{\prime} 50.56^{\prime \prime} \mathrm{N}, 6^{\circ} 27^{\prime} 50.39^{\prime \prime} \mathrm{E} ; 110 \mathrm{~m}$ a.s.l.). At the same site with the UHOH DIAL, the UHOH rotational Raman lidar (RRL) (Radlach et al., 2008; Hammann et al., 2015) measured temperature and the KITcube (Kalthoff et al., 2013) observed - among others - the wind field with scanning Doppler lidar systems (Träumner, 2010) and the surface energy balance (Kalthoff et al., 2006; Krauss et al., 2010). The UHOH DIAL provided measurements of more than $180 \mathrm{~h}$ in 18 intensive observation periods (IOPs) in vertical and different scanning modes. The high-resolution fields of the measured thermodynamic variables are also used to derive higher-order moments of turbulent fluctuations (Muppa et al., 2016; Behrendt et al., 2015a) as well as sensible and latent heat fluxes (Wulfmeyer et al., 2014; Behrendt et al., 2015b). This data set will be used for the verification of current approaches of turbulence parameterizations as well as of the development and tests of new turbulence parameterizations. Further details are found in Wulfmeyer et al. (2016).

\subsection{Performance and analyses of RHI scans}

Our measurements were performed during IOP 4 on 20 April 2013. On this day, the HOPE domain was under the influence of a high pressure system located with its center over the Baltic Sea. The main wind direction was northeast to east as confirmed by the radiosoundings. Figure 4 shows temperature, humidity, and wind velocity profiles of the radiosonde launched at 07:00 UTC at the lidar site. The horizontal wind speed within the ABL was between 8 and $10 \mathrm{~m} \mathrm{~s}^{-1}$ with a minimum of $5.5 \mathrm{~m} \mathrm{~s}^{-1}$ at a height of $1250 \mathrm{~m}$ above ground level of the lidar site (a.g.l.). Temperature and absolute humidity were quite low on this day with ground values of only $5^{\circ} \mathrm{C}$ and $4.5 \mathrm{~g} \mathrm{~m}^{-3}$, respectively. Between 06:00 and 07:00 UTC (local time was UTC+2), only thin cirrus clouds were present at heights between 7 and $8 \mathrm{~km}$ as found by the offline backscatter signal. The surface temperature profile shows that a very shallow unstable surface layer started to develop by surface heating but it was not deeper than $200 \mathrm{~m}$. 

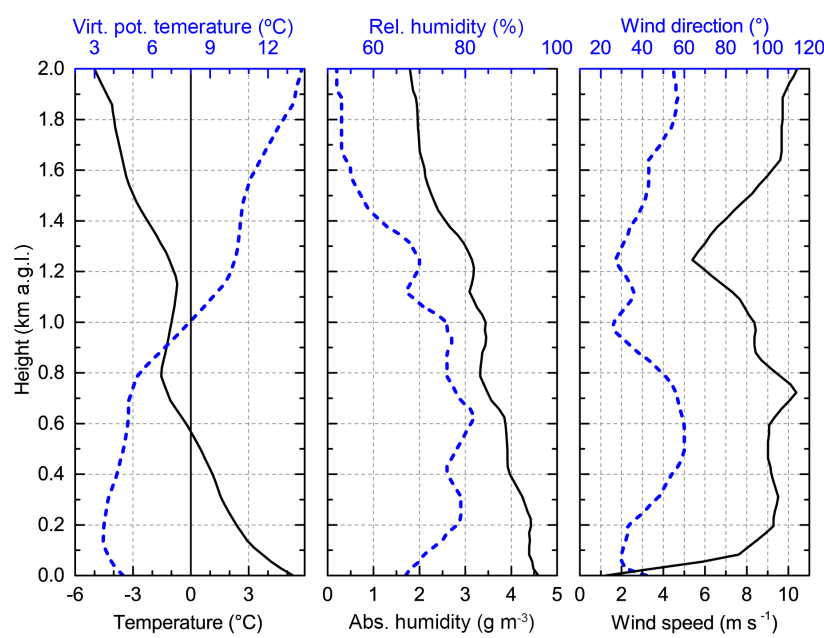

Figure 4. Profiles of temperature, virtual potential temperature, absolute and relative humidity, horizontal wind speed, and wind direction measured with the radiosonde on IOP 5 on 20 April 2013 at 07:00 UTC.

The complex vertical layering is particularly visible in the absolute humidity profile, which shows a series of moisture layers with a thickness of 100 to $200 \mathrm{~m}$, up to $1.4 \mathrm{~km}$ a.g.l. However, the virtual potential temperature profile shows that the top of the residual layer was at around $800 \mathrm{~m}$ a.g.l., while the top of the developing mixed layer was at $200 \mathrm{~m}$ a.g.l. There was another temperature inversion at around $1.6 \mathrm{~km}$ a.g.l. that may be related to more synoptic meteorological conditions such as large-scale subsidence.

RHI scanning measurements of the humidity field in the HOPE region were performed on 20 April 2013 between 06:03 and 07:24 UTC. The time resolution for this analysis is $10 \mathrm{~s}$. With a scan speed of $0.15^{\circ} \mathrm{s}^{-1}$, this results in an angle resolution of $1.5^{\circ}$. With a covered elevation angle range of $85^{\circ}$ each of these RHI scans took around $10 \mathrm{~min}$. Due to the longer path of the laser beam through the aerosol-loaded air in lower elevation and the corresponding higher extinction as well as due to the higher moisture in the boundary layer and the corresponding stronger attenuation of the online signal, we averaged the data according to the following procedure. We calculated the absolute humidity with different range resolutions $\Delta R$ to keep the angle resolution. Afterwards, the radial data were gridded to a horizontal-vertical grid with a resolution of $50 \mathrm{~m}$. Finally, the data with different resolutions were merged according to the horizontal distance: up to a distance of $1.3 \mathrm{~km} \Delta R=142.5 \mathrm{~m}$, up to $2.5 \mathrm{~km} \Delta R=307.5 \mathrm{~m}$, up to $3.0 \mathrm{~km} \Delta R=457.5 \mathrm{~m}$, and up to $4.2 \mathrm{~km} \Delta R=997.5 \mathrm{~m}$.

A noise error analysis was carried out as described in Sect. 3 and profiles for the horizontal distances of 1.3, 2, 3, and $4 \mathrm{~km}$ are shown in Fig. 5. For all distances, the error profiles show a significant increase above the top of the ABL because there are much fewer aerosol particles present which

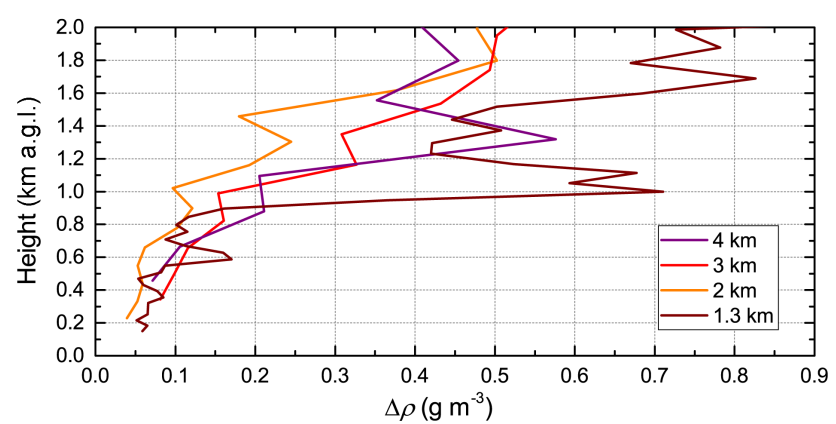

Figure 5. Instrumental noise profiles of the RHI scans shown in Fig. 6 for horizontal distances (range resolution) of $1.3 \mathrm{~km}(\Delta R=$ $142.5 \mathrm{~m}), 2 \mathrm{~km}(\Delta R=307.5 \mathrm{~m}), 3 \mathrm{~km}(\Delta R=497.5 \mathrm{~m})$, and $4 \mathrm{~km}$ $(\Delta R=997.5 \mathrm{~m})$ with a temporal resolution of $10 \mathrm{~s}$.

act as scatterers. The top of the ABL height increases from the near range $(1.3 \mathrm{~km})$ to the far range $(4 \mathrm{~km})$. At a horizontal distance of $1.3 \mathrm{~km}$ the top of the ABL is at $0.9 \mathrm{~km}$ a.g.l. while it is $200 \mathrm{~m}$ higher $(1.1 \mathrm{~km}$ a.g.l) at a distance of $4.0 \mathrm{~km}$. Below the top of the ABL, the noise values are below or around $0.2 \mathrm{~g} \mathrm{~m}^{-3}$, and above the top of the ABL the noise reaches values between 0.5 and $0.8 \mathrm{~g} \mathrm{~m}^{-3}$. This results in an upper limit of a relative noise error of $<6 \%$ within the ABL. The noise profile for $1.3 \mathrm{~km}$ distance does not show the smallest values but this is maybe due to the assumption of neglecting atmospheric fluctuations which become relatively larger when the instrumental noise decreases.

Figure 6 shows scanning humidity measurements in the HOPE region on 20 April 2013 between 06:03 and 07:24 UTC. The measurements were performed towards the two other experimental sites of the HOPE campaign: towards the Leipzig Aerosol and Cloud Research Observations System (LACROS) southwards and towards the Jülich ObservatorY for Cloud Evaluation (JOYCE) southwestwards. The plots are geolocated to the Earth surface and cover a horizontal range of 0.7 to $4.2 \mathrm{~km}$ up to an altitude of $2 \mathrm{~km} \mathrm{a.g.l.}$ In the near range of the RHI scans we omitted the data up to $950 \mathrm{~m}$ because of no full overlap of the field of view of the transmitting and receiving telescopes.

The WV field in the two scanning directions showed several similarities but also significant differences, revealing the heterogeneities of the ABL in the region. In both directions, three moist layers with drier layers in between can be identified. The altitudes of the layers differ significantly. Towards LACROS, the moist layers were at 500, 1100 , and $1500 \mathrm{~m}$ a.g.l. while towards JOYCE they were at 300,1000 , and $1400 \mathrm{~m}$ a.g.l. for the measurements for the first two scans between 06:03 and 06:27 UTC (Fig. 6a). One hour later (Fig. 6b), the measurements show the same number of layers but the height of the lowest one increased to 600 and $500 \mathrm{~m}$ a.g.1. for LACROS and JOYCE directions, respectively. 

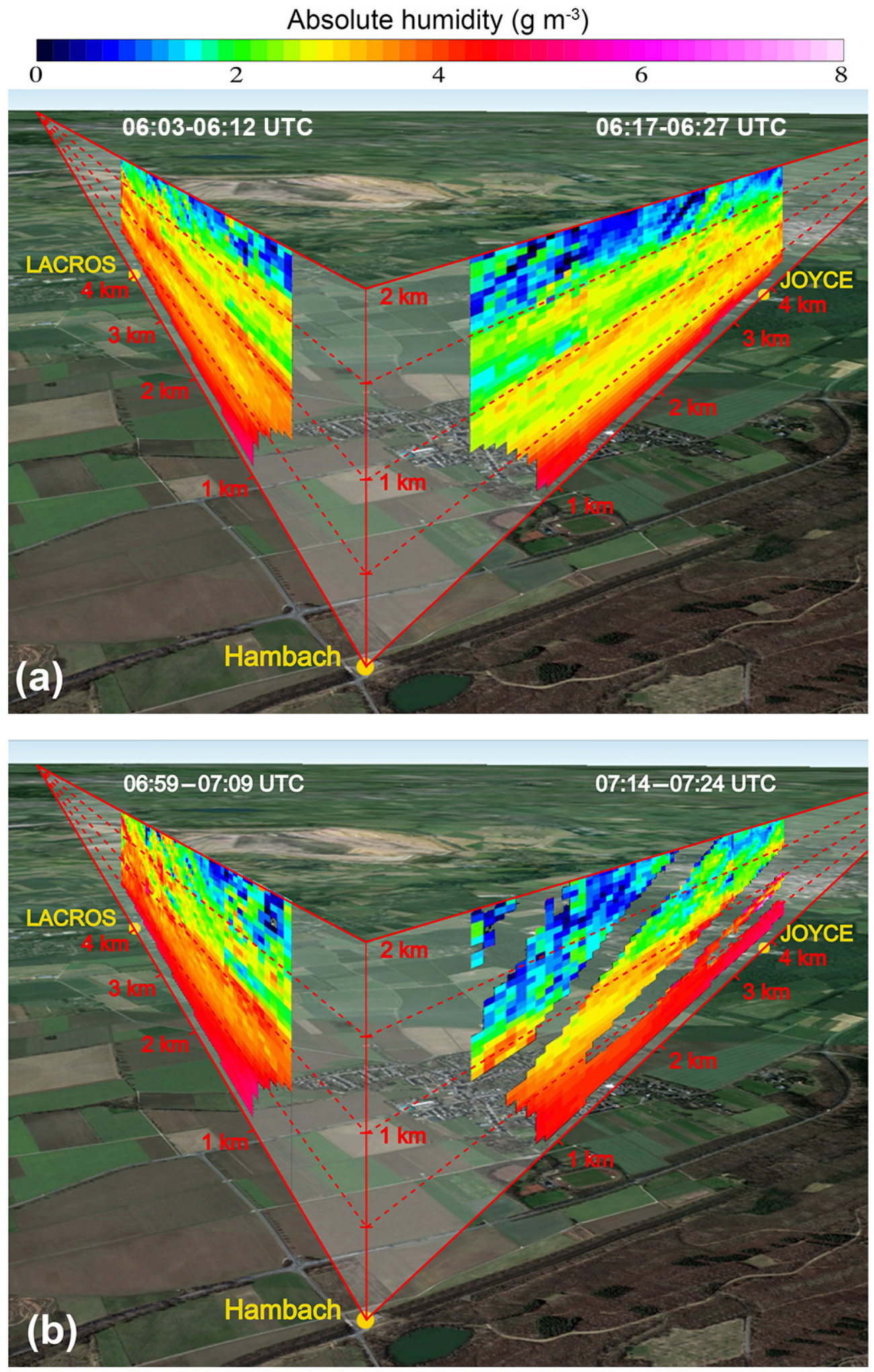

Figure 6. 3-D illustration of the WV field in the HOPE domain. The scanning measurements were performed towards LACROS and JOYCE on IOP 4 on 20 April 2013 between (a) 06:03 and 06:27 UTC and (b) 06:59 and 07:24 UTC. The UHOH DIAL system was located at the Hambach site and scanned towards the other supersites LACROS and JOYCE. The distances to the other sites were around $4 \mathrm{~km}$. In (b) the gaps in the data occur from clouds at the top of the CBL. Background image from Google Earth. 


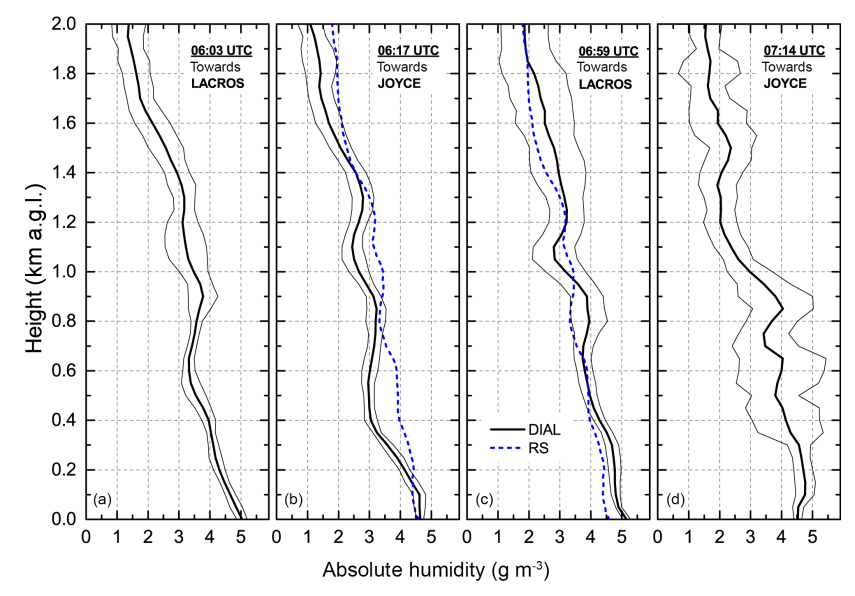

Figure 7. Spatially averaged humidity profiles of the scanning measurements of Fig. 6. The profiles in (a) are of the scans towards LACROS and in (b) towards JOYCE. The thick solid lines show the mean profiles of each scan and the thin lines indicate the horizontal variability of humidity ( $1 \sigma$ standard deviation) within the scan range. The radiosonde profile at 07:00 UTC was plotted with a dashed line with the two closest scans (b and $\mathbf{c}$ ).

In general, we see that the ABL was more moist in the direction of LACROS than in the direction of JOYCE. In order to illustrate this, we have averaged the scanning data horizontally. The averaged vertical humidity profiles of the four RHI measurements of Fig. 6 are shown in Fig. 7. In the profiles, the layer structure discussed above can be identified. The humidity profile of the radiosonde at 07:00 UTC does not fit with an averaged DIAL profile and shows also different structures but the profile stays within the variability of the DIAL measurement towards LACROS. However, different to the DIAL measurements, a radiosonde measures only along its flight path and, thus, can only sample a snapshot of the atmospheric constitution. In this case, northeasterly wind caused a horizontal wind-driven displacement of the radiosonde of about $3 \mathrm{~km}$ when it reached an altitude of $2 \mathrm{~km}$ a.g.l. The horizontal variability within a certain range can also only be determined with scanning DIAL measurements. For these reasons, horizontally averaged profiles of scanning DIAL measurements are better suited for comparisons with model simulation outputs which also give profiles representative of a whole model grid box (Milovac et al., 2016).

Interestingly, in one of the scans (Fig. $6 \mathrm{~b}$ towards JOYCE) clouds appear, while all others are cloud-free. Four clouds can be identified in the offline backscatter signals at distances and altitudes of 300 and $700 \mathrm{~m}$ a.g.l., of 600 and $600 \mathrm{~m}$ a.g.l., of $1.5 \mathrm{~km}$ and $500 \mathrm{~m}$ a.g.l., and of $3 \mathrm{~km}$ and $500 \mathrm{~m}$ a.g.l., respectively. The large extinction of the clouds prohibits measurements inside the clouds and beyond, resulting in radial structured gaps in the data (plotted transparently in Fig. 6b). At $560 \mathrm{~m}$ a.g.l. the profiles of the radiosonde (Fig. 4) show a zero-crossing in the temperature and a relative humidity of only about $80 \%$. The DIAL measurements show values of about 4.5 and $5 \mathrm{~g} \mathrm{~m}^{-3}$ below the clouds at 1.5 and $3 \mathrm{~km}$ distance, respectively. As at least $100 \%$ relative humidity is needed for cloud formation, this corresponds to a required absolute humidity of $4.8 \mathrm{~g} \mathrm{~m}^{-3}$ at a temperature of $0^{\circ} \mathrm{C}$. Clearly, the observed clouds are related to locally higher moisture values as revealed by the DIAL scans, which are also seen in Fig. $7 \mathrm{~d}$ by an upper limit of the $1 \sigma$ standard deviation above $5 \mathrm{~g} \mathrm{~m}^{-3}$ in heights between 300 and $700 \mathrm{~m}$ a.g.l. The measurement $1 \mathrm{~h}$ before already showed these humidity values at around $250 \mathrm{~m}$ a.g.l. altitude, which was not sufficient to reach saturation but indicate that the humidity came from the ground and reached the condensation level during the last scan.

\section{Volume scans for the investigation of the 3-D water vapor field}

\subsection{Instrumental setup}

With volume scans, the relation of the moisture field to surface properties can be investigated more in detail. The observation of 3-D humidity is either possible by a series of fast RHI scans using different azimuth angles or by a series of continuous $360^{\circ}$ scans with different elevation angles.

For the first time with the UHOH DIAL, the latter configuration was applied during the Surface Atmosphere Boundary Layer Exchange (SABLE) field campaign in August 2014. The SABLE campaign took place near Pforzheim $\left(48^{\circ} 55^{\prime} 45.85^{\prime \prime} \mathrm{N}, 8^{\circ} 42^{\prime} 19.57^{\prime \prime} \mathrm{E}\right.$; $320 \mathrm{~m}$ a.s.l.) in the Black Forest (southwest Germany) as part of the Research Unit 1695 "Regional Climate Change" of the German Research Foundation (DFG; see https://klimawandel.uni-hohenheim. de/startseite?\&L=1). The UHOH DIAL was collocated with the UHOH RRL for temperature measurements and with three Doppler lidar systems for measuring the wind velocities as well as with a synergy of surface in situ sensors distributed in the fields, e.g., eddy covariance stations (Wizemann et al., 2015). The results of these campaigns shall contribute to an improved understanding of the relations between surface properties and boundary layer characteristics, shallow cumulus convection, as well as convection initiation.

During the special observations period (SOP) 2 on $22 \mathrm{Au}-$ gust 2014, the 3-D WV field was observed with a volume scan. On this day, a low pressure system over Scandinavia and a high pressure system over eastern Europe provoked westerly flow in the SABLE domain. Stratus clouds occurred over the measurement site with a bottom height of about $2.5 \mathrm{~km}$ a.g.l. These clouds reduced the surface heating, so no convective boundary layer formed. Consequently, we can assume that the structures of the moisture field were largely advected and modified locally mainly by orography. There was a small hill with a top height of $375 \mathrm{~m}$ a.s.l. at $0.6 \mathrm{~km}$ distance to the south while the terrain in the near range of 


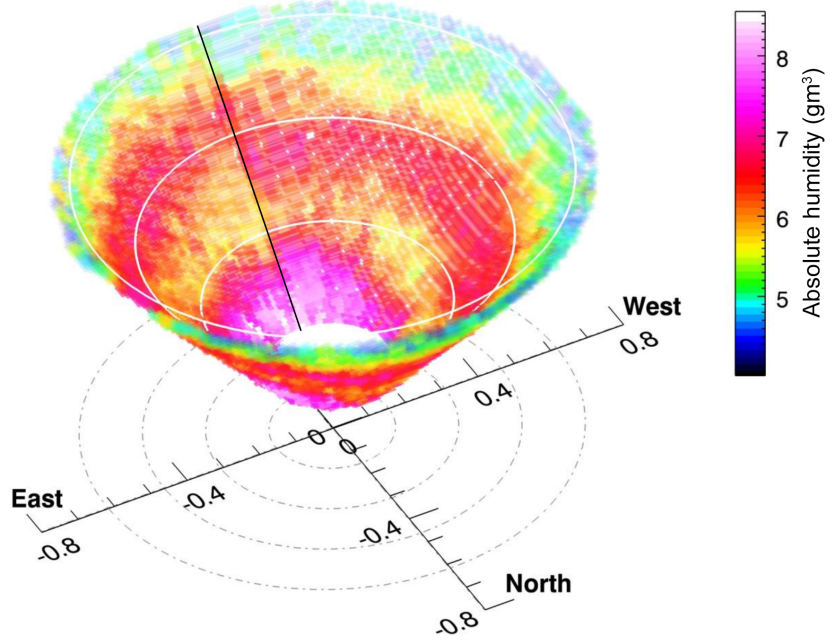

Figure 8. Conical scan of SOP 2 on 22 August 2014 between 08:40 and 08:55 UTC. The cone has an elevation angle of $50^{\circ}$. The data were plotted for a height range from 0.2 up to $0.8 \mathrm{~km}$ a.g.l. The white circles indicate the height in $0.2 \mathrm{~km}$ steps and the grey dashedpointed circles show their projection down to the ground. The black solid line marks the start and end direction of the conical scan; the scanner unit moved clockwise. The scales are given in $\mathrm{km}$.

the lidar was mainly flat. The radiosonde from 09:30 UTC showed at the ground a temperature of $16^{\circ} \mathrm{C}$ and a relative humidity of $60 \%$. The wind was calm $\left(<1.5 \mathrm{~m} \mathrm{~s}^{-1}\right)$ at the ground up to $300 \mathrm{ma}$ a.g.l. and increased then to $6 \mathrm{~m} \mathrm{~s}^{-1}$ at $600 \mathrm{~m}$ a.g.l. in an east-northeast direction.

\subsection{Performance and analyses of the volume scan}

The area around the DIAL site was observed by performing a series of $360^{\circ}$ conical scans around the vertical with elevation angles of $50,60,70,80$, and $90^{\circ}$. Figure 8 shows a 3-D view of the $50^{\circ}$ cone of the volume scan between 08:40 and 09:40 UTC. For this measurement, the scan speed was $0.4^{\circ} \mathrm{s}^{-1}$, resulting in a total duration of $15 \mathrm{~min}$ per cone. Consequently, the full volume with five cones was scanned within $75 \mathrm{~min}$. The start and the end directions were southward-oriented and the scanner moved for the 50, 70, and $90^{\circ}$ cone clockwise and counter-clockwise for the other scans of 60 and $80^{\circ}$. The WV calculation was performed with $10 \mathrm{~s}$ averaged profiles and a $67.5 \mathrm{~m}$ range resolution. For plotting, the WV data were transferred from the polar coordinates to Cartesian coordinates and each profile was expanded over an azimuth range of $4^{\circ}$.

The instrumental noise was determined with the method of Lenschow et al. (2000) for each elevation angle separately. Profiles of the absolute and relative noise are shown in Fig. 9. Above $400 \mathrm{~m}$ a.g.l., the noise level increases with height. The noise at the same height a.g.l. is higher for lower elevation angles than for higher elevation angles because the range for the same height a.g.l. is larger. The profile of the low-
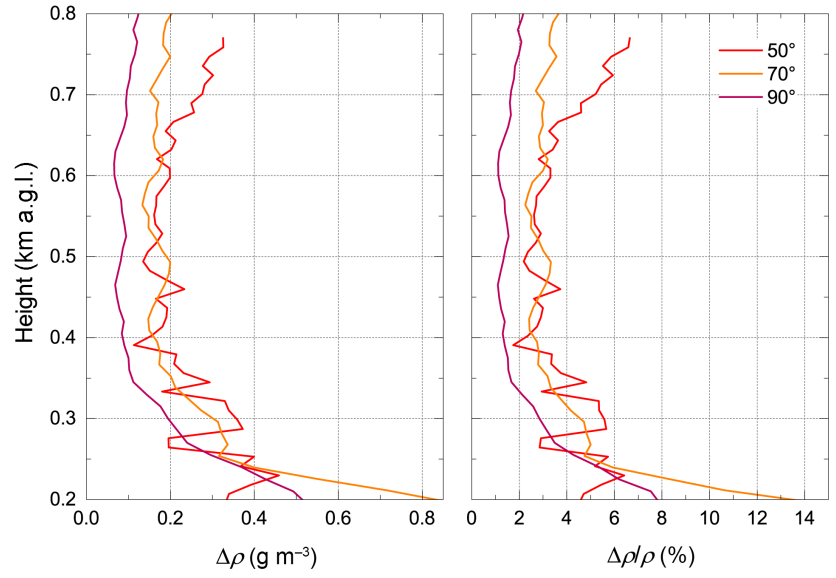

Figure 9. Absolute noise $\Delta \rho$ and relative noise $\Delta \rho / \rho$ profiles of selected parts of the volume scan with the corresponding temporal and spatial resolution of $10 \mathrm{~s}$ and $67.5 \mathrm{~m}$, respectively.

est elevation angle shows a maximum noise of $<0.35 \mathrm{~g} \mathrm{~m}^{-3}$ or $<7 \%$ at $750 \mathrm{~m}$ altitude a.g.l. Below $400 \mathrm{~m}$ a.g.l., the noise also increases, but here due to overlap effects. However, this does not occur in the absolute humidity data as the noise is $<0.8 \mathrm{~g} \mathrm{~m}^{-3}$.

The measurement in Fig. 8 shows two moist layers. The lower layer reached altitudes up to between 300 and $400 \mathrm{~m}$ a.g.l. with humidity values of $7-8 \mathrm{~g} \mathrm{~m}^{-3}$. This layer was topped by a drier layer with $5.6 \mathrm{~g} \mathrm{~m}^{-3}$ and a second moist layer at $600 \mathrm{ma.g} .1$. with a humidity of about $6.5 \mathrm{~g} \mathrm{~m}^{-3}$.

To get an insight into the whole volume, Fig. 10a shows cross sections and illustrates the whole data set of the volume scan three-dimensionally. In addition and for orientation, the cutting planes are depicted of which the water vapor distribution is then shown in Fig. 10b-i. The figure contains three vertical cross sections in a north-south direction (panel b-d) and three in a west-east direction (panel e-g) as well as horizontal cross section planes at two height levels (panel h-i). The vertical cross section images depict the vertical structure at different distances to the DIAL similar to what was shown above with RHI scans. In Fig. 10b-g the vertical planes are positioned at \pm 0.2 and $0.0 \mathrm{~km}$ distance with respect to the vertical line above the DIAL location. The horizontal cross section plane can also of course be placed at any height of interest. These plots show the WV distribution with respect to the azimuth angle but in contrast to conical scan plots, the data are not shown along the line of sight but rather at one height the data of all conical scans of different elevation angles of the volume scan are shown. The cross section images depict also the moist layers in the two lower elevation angle scans.

The heights of the layers in Fig. 10 are almost similar for all directions. Because of the full cloud cover on this day, convection was very weak and no large eddies were initiated. 


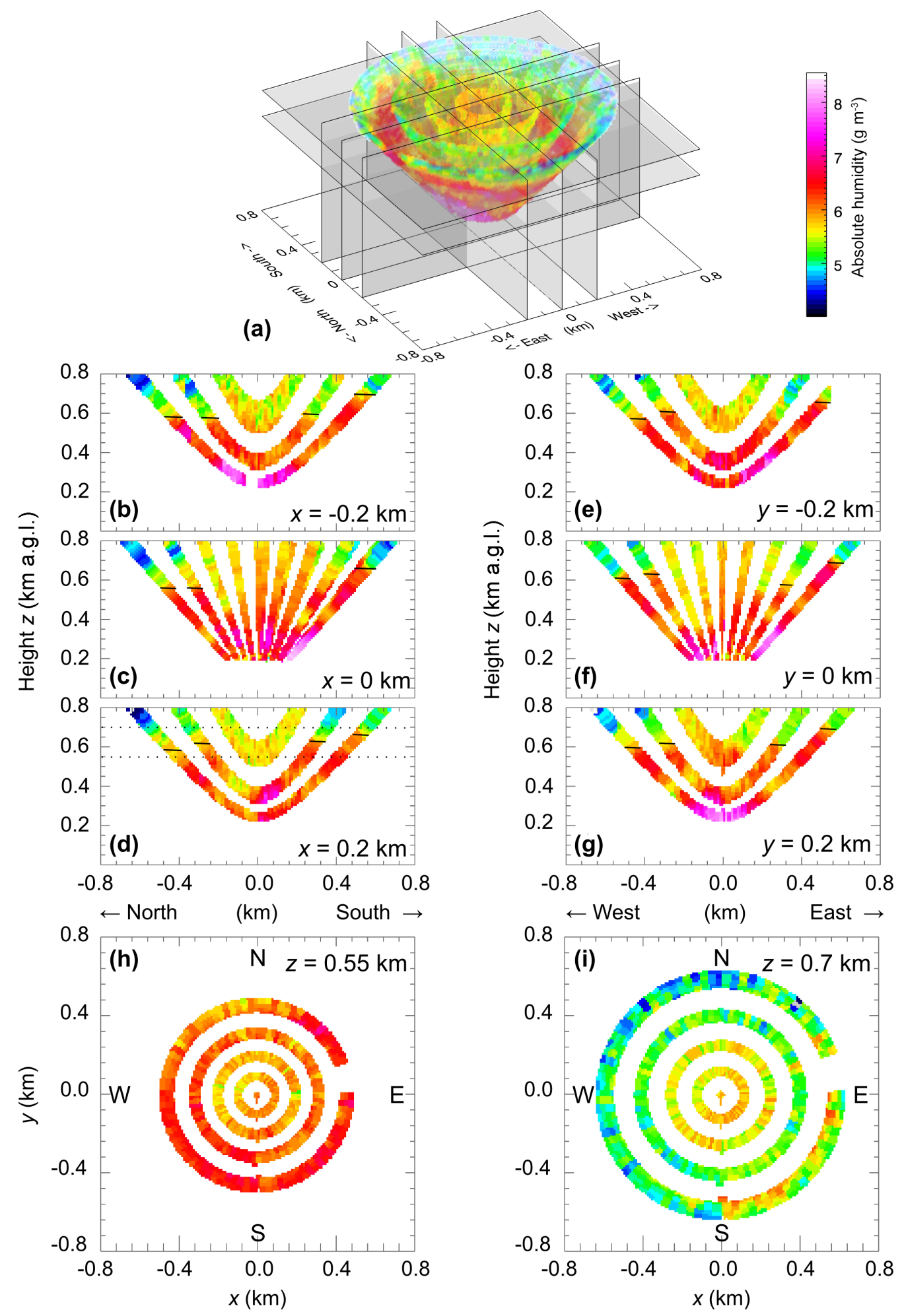

Figure 10. Cutting planes through the 3-D data set provides cross section images. (a) Schematic illustration of the 3-D data set with the cutting planes. (b-i) Horizontal and vertical cross section images of the different cutting plans of (a). The black lines in (b-g) indicate the top of the boundary layer. The dotted lines in (a) illustrate the location of the horizontal planes (h-i). 
Thus, the moist layer from the ground grew slowly and varied according to underlying orography. Here, in south direction at a distance of $0.6 \mathrm{~km}$ from the DIAL a small hill was located with an increase of the surface elevation of about $55 \mathrm{~m}$. The measurements of the lowest elevation angle in Fig. 10b-d show indeed a higher altitude of the boundary layer of about $50 \mathrm{~m}$ at a distance of $0.5 \mathrm{~km}$ southwards. Also to the east a small trend to higher altitudes of the top of the boundary layer can be observed. This is also indicated by the horizontal plane image in Fig. 10i for the southeasterly direction and a distance of $0.6 \mathrm{~km}$. This area corresponds in our case to the lee side of the small hill; therefore the higher moisture might be explained by a modification of the moisture field by shifted overflow lifting.

Averaging the volume data horizontally provides the mean humidity profile. The profile was plotted in Fig. 11 up to an altitude of $0.8 \mathrm{~km}$ a.g.l. The thin lines mark the horizontal WV variability similar to Fig. 7 . The radiosonde profile at 09:30 UTC is given in the diagram as well. Again, there were differences between DIAL and radiosonde measurements but the radiosonde captured similar moisture layers and stayed almost within 1 standard deviation of the DIAL profile.

\section{Low-elevation range-height indicator scans for the investigation of the surface layer}

\subsection{Instrumental setup}

On 12 August 2014 the SABLE domain was under westerly flow due to low pressure systems located over the Baltic Sea and Scandinavia, one day before a cold front passed through the measurement area. Vertical DIAL measurements before and after the scanning measurements (not shown here) indicate a CBL height of between 1.0 and $1.5 \mathrm{~km}$ a.g.l. and a residual layer up to $2 \mathrm{~km}$ a.g.l. The WV content in these two layers was up to $8 \mathrm{~g} \mathrm{~m}^{-3}$ and around $5 \mathrm{~g} \mathrm{~m}^{-3}$, respectively. During the scanning period, cirrus clouds at $8 \mathrm{~km}$ a.g.l. were present and also few low-level clouds at $2-2.5 \mathrm{~km}$ a.g.l. at the top of the CBL but these clouds did not inhibit large surface fluxes (sensible heat flux $100 \mathrm{~kW} \mathrm{~m}^{-2}$ and latent heat flux $240 \mathrm{~W} \mathrm{~m}^{-2}$ between 11:00 and 12:00 UTC) and the development of a CBL. The radiosonde profiles from 10:30 UTC measured a temperature of about $18^{\circ} \mathrm{C}$ and a relative humidity of $60 \%$ at the ground. The relative humidity increased with height and reached $80 \%$ at the top of the CBL. The wind speed was low with $4-5 \mathrm{~m} \mathrm{~s}^{-1}$ at the surface and increased linearly with height; the wind direction was west.

In order to observe the surface layer, measurements are needed which reach as close as possible to the land surface or the canopy level. Due to incomplete overlap of the outgoing laser beam and the field of view of the receiver in the near range, vertical measurements of the UHOH DIAL start only a few hundred meters above ground. With low-level RHI scans, these low-level measurements can be realized. Fur-

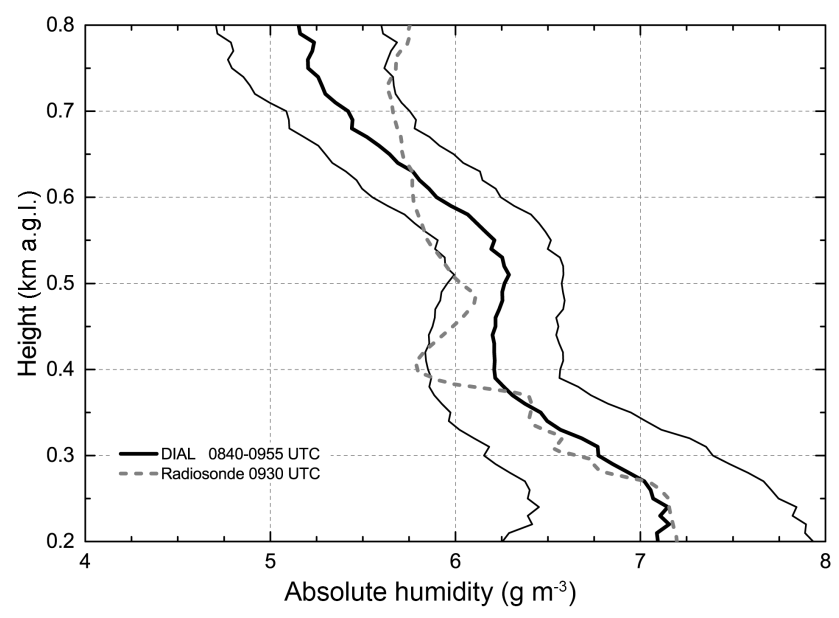

Figure 11. Spatially averaged absolute humidity profiles of the volume scan of Fig. 10 (08:40-09:55 UTC). The thick solid line shows the mean profile of the scanned volume and the thin lines indicate the horizontal WV variability ( $1 \sigma$ standard deviation) within the scan range. The radiosonde profile launched at 09:30 UTC was plotted with a dashed line.

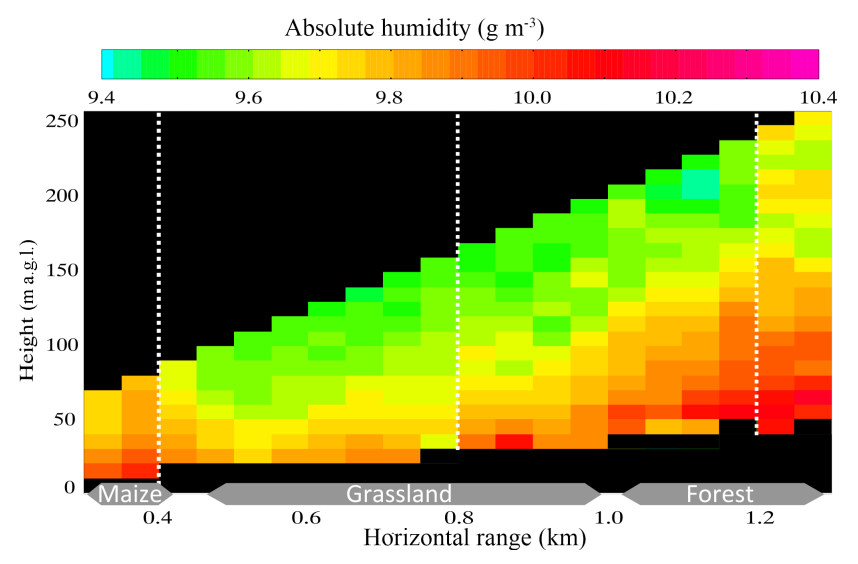

Figure 12. One-hour mean WV field between 11:00 and 12:00 UTC on IOP 4 on 12 August 2014. The covered angle range was 0 to $12^{\circ}$; the scan speed was $0.2^{\circ} \mathrm{s}^{-1}$; a single scan took $1 \mathrm{~min}$. For the water vapor calculation, $1 \mathrm{~s}$ averaged data were used. The land cover along the line of sight is also shown. The dotted lines indicate the location of the vertical profiles shown in Fig. 13

thermore, the variations in the humidity structures can be related to different types of land use along the line of sight of the low-level scanning measurements.

During the SABLE campaign (see Sect. 5), these lowlevel scanning measurements were performed to investigate the properties of the atmospheric surface layer. The lowelevation scans covered elevation angles between 0 and $12^{\circ}$. In order to reach a high vertical resolution, the scan speed was $0.2^{\circ} \mathrm{s}^{-1}$, which resulted in a time duration of $1 \mathrm{~min}$ per scan. 


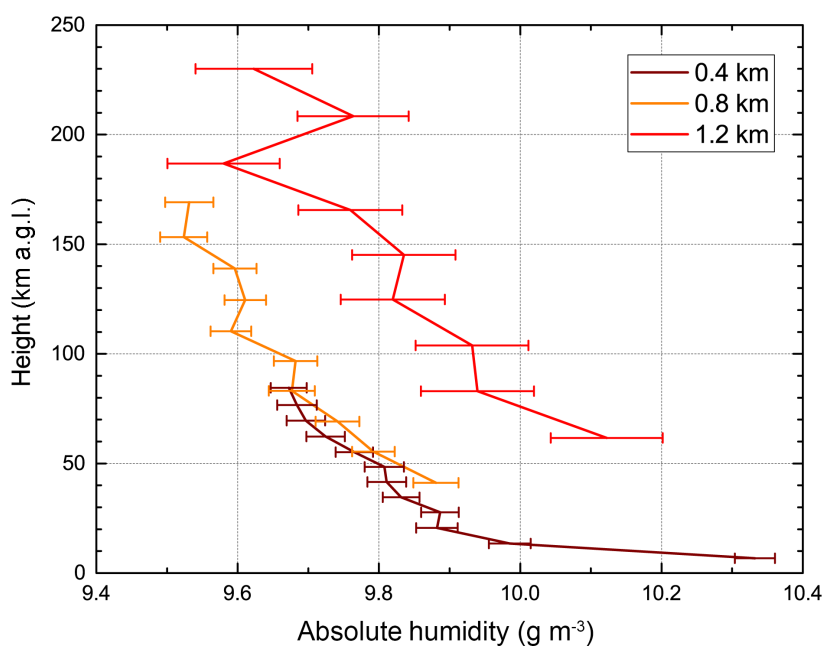

Figure 13. Absolute humidity profiles for the RHI scan of Fig. 12 for the horizontal distances of $0.4,0.8$, and $1.2 \mathrm{~km}$. The noise errors are also shown. The location of the $\mathrm{WV}$ and noise profiles are indicated by the dotted white lines in Fig. 12.

\subsection{Performance and analyses of the low-level RHI scans}

Low-elevation scanning measurements were performed during the SABLE campaign on IOP 4 on 12 August 2014 between 11:00 and 12:00 UTC. The results are presented in Fig. 12. For the WV calculation, $1 \mathrm{~s}$ averaged profiles and a SaGo window length of $135 \mathrm{~m}$ were used. All scans of the $1 \mathrm{~h}$ period (52 scans) were averaged with $1^{\circ}$ angle resolution, resulting in a final time resolution of $260 \mathrm{~s}$. Then, the data were gridded to an $x-y$ grid with a resolution of $50 \mathrm{~m} \times 10 \mathrm{~m}$. With the high spatial resolution, small variations in the absolute humidity values (notice color scale $9.4-10.4 \mathrm{~g} \mathrm{~m}^{-3}$ in Fig. 12) at different heights and distances can be identified.

The instrumental noise for the low-elevation scan was estimated with the ACF method. The data were used in the initial radial polar coordinates and data points of all scans at a certain range bin covering a $1^{\circ}$ angle range were selected for the ACF calculation. The resulting errors were then scaled with Eq. (6) from the $1 \mathrm{~s}$ time resolution. In Fig. 13, the noise errors were plotted as error bars with the absolute humidity profiles at the distances of 400,800 , and $1200 \mathrm{~m}$, respectively. All three profiles show a constant noise level for the whole profile which can be expected for the small covered height range because all data points of one profile belong to a similar range bin and as the profile stays within in the boundary layer the optical thickness is constant over the whole height range. Of course, the noise level increases with distance but the noise value stays lower than $0.3 \mathrm{~g} \mathrm{~m}^{-3}$ for $400 \mathrm{~m}$, lower than $0.4 \mathrm{~g} \mathrm{~m}^{-3}$ for $800 \mathrm{~m}$, and lower than $0.9 \mathrm{~g} \mathrm{~m}^{-3}$ for $1200 \mathrm{~m}$. These values translate to relative values of less than $0.3 \%$, less than $0.4 \%$, and less than $1 \%$, respectively.
The humidity values close to the ground are higher than above and at $1200 \mathrm{~m}$ distance the humidity was higher than at $800 \mathrm{~m}$ distance. Because these measurements are close to the ground, it is possible to relate these changes in horizontal direction to the vegetation at the ground. For the measurement in Fig. 12, the vegetation can be separated into three categories. In the near range up to $450 \mathrm{~m}$ there was a maize field, up to $1050 \mathrm{~m}$ the ground was covered with grassland, and further away we scanned over forest. The terrain around the DIAL site was mainly flat except for a small hill in a southern direction at a distance of $0.6 \mathrm{~km}$ reaching an altitude of $375 \mathrm{~m}$ a.s.l. Along the scan direction towards a southwesterly direction; the terrain profile was flat for the maize field and slightly uphill for the grassland, while the forest was located on the small hill at a distance of $1300 \mathrm{~m}$. The measurement in Fig. 12 shows that there was more water vapor in the atmosphere above the maize field and above the forest, which was likely due to higher evapotranspiration than above the grassland.

This $1 \mathrm{~h}$ mean profile close to the ground is similar to what was measured by Eichinger et al. (2000) with a scanning Raman lidar. However, with the WVDIAL technique a larger range can be investigated. In the future, such data can be used to estimate the spatial distribution of the latent heat flux over different kinds of land cover (Wulfmeyer et al., 2014). For this purpose, the Monin-Obukhov similarity theory (MOST) (Monin and Obukhov, 1954; Brutsaert, 1982) can be applied using the slope of such a vertical humidity profile and simultaneously obtained friction velocity $u^{*}$.

\section{Summary and outlook}

The measurements of the spatial distribution of water vapor by the UHOH DIAL in three different scanning modes were presented. The UHOH DIAL uses a frequency-stabilized Ti:sapphire resonator as laser transmitter and emits laser pulses at $818 \mathrm{~nm}$. The output power for scanning measurements is currently limited to $1.6 \mathrm{~W}$ due to the maximum power which can be transmitted by the optical fiber used. The $20 \mathrm{~cm}$ transmitting and $80 \mathrm{~cm}$ receiving telescopes form the scanner unit which allows scanning measurements of the whole hemisphere $\left(180^{\circ}\right.$ elevation, $360^{\circ}$ azimuth) with scan speeds between 0.1 and $6^{\circ} \mathrm{s}^{-1}$. For data analyses typical range and temporal resolutions of $50-300 \mathrm{~m}$ and $1-10 \mathrm{~s}$, respectively, are used. A new method to determine the noise level of scanning measurements was developed and shows uncertainties of $<7 \%$ within the ABL. With the DIAL technique it is now possible to determine 3-D WV fields with high temporal and spatial resolution including a specific analysis of noise error fields. Therefore, the significance of WV structures in these 2-D and 3-D fields can be studied and specified in great detail.

Scanning measurements in RHI mode were performed in two directions during HOPE with elevation angles from 
5 to $90^{\circ}$ up to a horizontal distance of $4 \mathrm{~km}$. With these scans the humidity field was investigated regarding turbulent and mesoscale variability as well as cloud formation. Similar layers for both directions but also differences in altitudes of the layers or in the WV content were observed in the WV field. Four scans depict the evolution of the layers within $90 \mathrm{~min}$. In the last measurement of the series, clouds appear at the top of the lowest moist layer where the conditions of $100 \%$ relative humidity for cloud formation were locally fulfilled. Horizontally averaged vertical profiles show also a higher humidity variability for that measurement. The noise at the top of the ABL increases strongly but the noise error remains $<6 \%$ within the ABL.

For the first time, a conical volume scan performed during the SABLE campaign presents the 3-D spatial WV distribution within a distance range of $0.8 \mathrm{~km}$ around the DIAL. The data show two moist layers with some variations in height for different directions. These variations can be related to variations in the surface elevation, e.g., in a southeast direction a small hill with a slightly higher elevation was located. The instrumental noise for this case was calculated to be $<0.5 \mathrm{~g} \mathrm{~m}^{-3}$ or $<7 \%$.

Low-elevation scanning measurements revealed the humidity structures close to the ground. The presented data were averaged over $1 \mathrm{~h}$ of scanning measurements and cover a height range from 20 to $140 \mathrm{ma}$ a.g.l. of the instrument. The horizontal variation of the WV field can be related to the heterogeneity of the vegetation at the ground. The errors for these kinds of measurements were estimated to be $<0.3 \mathrm{~g} \mathrm{~m}^{-3}$ or $<0.3 \%$ at $400 \mathrm{~m}$ and $<0.9 \mathrm{~g} \mathrm{~m}^{-3}$ or $<1 \%$ at $1200 \mathrm{~m}$ horizontal distance throughout the measured height range.
In conclusion, all scanning modes are applicable to observe the spatial distribution of water vapor in the lower atmosphere. Depending on the focus of the research, the scan pattern can be adapted regarding the covered elevation and azimuth angle ranges.

In future work, these kinds of measurements can be extended to estimate evapotranspiration above different land cover and soil types using the Monin-Obukhov similarity theory. More measurements over different terrains and a larger set of vegetation types as well as under different meteorological conditions will be made. Furthermore, a combination with other instruments (temperature rotational Raman lidar, Doppler lidar, eddy covariance stations, towers, aircraft) will be highly beneficial. In this context, it will be very interesting to perform simultaneous observations of the surface layer and the top of the ABL for heat and WV budget studies. Comparison with LES will allow for validations and improvements of parameterization schemes regarding LA feedback which is essential for further advancements of numerical weather prediction models and climate projections. 


\section{Appendix A: Acronyms}

$\begin{array}{ll}\text { 3-D } & \text { three-dimensional } \\ \text { ABL } & \text { atmospheric boundary layer } \\ \text { ACF } & \text { autocovariance function } \\ \text { a.g.l. } & \text { above ground level of the lidar site } \\ \text { APD } & \text { avalanche photodiode } \\ \text { a.s.l. } & \text { above sea level } \\ \text { BR } & \text { beam reducer } \\ \text { CBL } & \text { convective boundary layer } \\ \text { CI } & \text { convection initiation } \\ \text { COPS } & \text { Convective and Orographically-induced Precipitation Study } \\ \text { DFB } & \text { distributed feedback } \\ \text { DIAL } & \text { differential absorption lidar } \\ \text { DLR } & \text { German Aerospace Center (Deutsches Zentrum für Luft- und Raumfahrt) } \\ \text { ECDL } & \text { external cavity diode laser } \\ \text { FC } & \text { fiber coupler } \\ \text { HD(CP) } & \text { High Definition of Clouds and Precipitation for advancing Climate Prediction } \\ \text { HITRAN } & \text { HIgh-resolution TRANsmission molecular absorption database } \\ \text { HOPE } & \text { HD(CP) })^{2} \text { Observational Prototype Experiment } \\ \text { HR } & \text { high-reflection mirror } \\ \text { IOP } & \text { intensive observation period } \\ \text { IR } & \text { infrared } \\ \text { IWV } & \text { integrated water vapor } \\ \text { JOYCE } & \text { Jülich ObservatorY for Cloud Evaluation } \\ \text { LA } & \text { land-atmosphere } \\ \text { LACROS } & \text { Leipzig Aerosol and Cloud Research Observations System } \\ \text { LES } & \text { large eddy simulations } \\ \text { MOST } & \text { Monin-Obukhov similarity theory } \\ \text { MWR } & \text { microwave radiometer } \\ \text { NASA } & \text { National Aeronautics and Space Administration } \\ \text { PD } & \text { photo diode } \\ \text { PM } & \text { primary mirror } \\ \text { RHI } & \text { range-height indicator } \\ \text { RRL } & \text { rotational Raman lidar } \\ \text { SABLE } & \text { Surface Atmosphere Boundary Layer Exchange } \\ \text { SaGo } & \text { Savitzky-Golay } \\ \text { SM } & \text { secondary mirror } \\ \text { SNR } & \text { signal-to-noise ratio } \\ \text { SOP } & \text { special observations period } \\ \text { TM } & \text { transmitting telescope mirror } \\ \text { UHOH } & \text { University of Hohenheim } \\ \text { UV } & \text { ultraviolet } \\ \text { WV } & \text { water vapor } \\ \text { WVDIAL } & \text { WV differential absorption lidar } \\ \text { WVRL } & \text { WV Raman lidar } \\ & \end{array}$


Acknowledgements. The HOPE campaign was funded by the German Research Ministry under the project number 01LK1212A.

The SABLE campaign was included in the Research Unit 1695 "Regional Climate Change" which was funded by the German Research Foundation (DFG) under the DFG Integrated Project PAK 346, project number WU 356-1 AOBJ: 591757.

Edited by: T. von Clarmann

\section{References}

Ansmann, A. and Bösenberg, J.: Correction scheme for spectral broadening by Rayleigh scattering in differential absorption lidar measurements of water vapor in the troposphere, Appl. Opt., 26, 15, 3026-3032, 1987.

Aoshima, F., Behrendt, A., Bauer, H.-S., and Wulfmeyer, V.: Statistics of convection initiation by use of the Meteosat Rapid Scan Service during the Convective and Orographically-induced Precipitation Study, Meteorol. Z., 17, 921-930, doi:10.1127/09412948/2008/0337, 2008.

Barnes, N. P. and Barnes, J. C.: Injection Seeding I: Theory, IEEE J. Quantum Electron., 29, 2670-2683, 1993a.

Barnes, J. C., Barnes, N. P., Wang, L. G., and Edwards, W.: Injection Seeding II: Ti: $\mathrm{Al}_{2} \mathrm{O}_{3}$ Experiments, IEEE J. Quantum Electron., 29, 2684-2692, 1993b.

Behrendt, A., Nakamura, T., Onishi, M., Baumgart, R., and Tsuda, T.: Combined Raman lidar for the measurement of atmospheric temperature, water vapor, particle extinction coefficient, and particle backscatter coefficient, Appl. Opt., 41, 7657-7666, 2002.

Behrendt, A., Wulfmeyer, V., Di Girolamo, P., Kiemle, C., Bauer, H.-S., Schaberl, T., Summa, D., Whiteman, D. N., Demoz, B. B., Browell, E. V., Ismail, S., Ferrare, R., Kooi, S., Ehret, G., Wang, J.: Intercomparison of water vapor data measured with lidar during IHOP_2002 - Part 1: Airborne to ground-based lidar systems and comparisons with chilled-mirror hygrometer radiosondes, $\mathrm{J}$. Atmos. Oceanic Technol., 24, 3-21, doi:10.1175/JTECH1924.1, 2007.

Behrendt, A., Wulfmeyer, V., Riede, A., Wagner, G., Pal, S., Bauer, H., Radlach, M., and Späth, F.: 3-Dimensional observations of atmospheric humidity with a scanning differential absorption lidar, in: Remote Sensing of Clouds and the Atmosphere XIV, edited by: Picard, R. H., Schäfer, K., Comeron, A., and van Weele, M., SPIE Conference Proceeding, 7475, 74750L, doi:10.1117/12.835143, 2009.

Behrendt, A., Pal, S., Aoshima, F., Bender, M., Blyth, A., Corsmeier, U., Cuesta, J., Dick, G., Dorninger, M., Flamant, C., Di Girolamo, P., Gorgas, T., Huang, Y., Kalthoff, N., Khodayar, S., Mannstein, H., Träumner, K., Wieser, A., and Wulfmeyer, V.: Observation of convection initiation processes with a suite of state-of-the-art research instruments during COPS IOP 8b, Q. J. Roy. Meteor. Soc., 137, 81-100, doi:10.1002/qj.758, 2011.

Behrendt, A., Blyth, A., Dorninger, M., Kalthoff, N., Flamant, C., Di Girolamo, P., and Richard, E.: Convective Precipitation in complex terrain: Results of the COPS campaign, Meteorol. Z., 22, 4, 367-372, doi:10.1127/0941-2948/2013/0541, 2013.

Behrendt, A., Wulfmeyer, V., Hammann, E., Muppa, S. K., and Pal, S.: Profiles of second- to fourth-order moments of turbulent temperature fluctuations in the convective boundary layer: first mea- surements with rotational Raman lidar, Atmos. Chem. Phys., 15, 5485-5500, doi:10.5194/acp-15-5485-2015, 2015a.

Behrendt, A., Wulfmeyer, V., Hammann, E., Muppa, S. K., Späth, F., Metzendorf, S., Riede, A., Karthoff, N., Maurer, V., and Wieser, A.: Atmospheric boundary layer studies with combined temperature rotational Raman lidar, water vapor DIAL, and Doppler lidar, 27th International Laser Radar Conference (ILRC 2015), New York, USA, 5-10 July 2015b.

Bengtsson, L., Hodges, K. I., and Hagemann, S.: Sensitivity of the ERA40 reanalysis to the observing system: determination of the global atmospheric circulation from reduced observations, Tellus A, 56, 456-471, doi:10.1111/j.1600-0870.2004.00079.x, 2004.

Bhawar, R., Di Girolamo, P., Summa, D., Flamant, C., Althausen, D., Behrendt, A., Kiemle, C., Bosser, P., Cacciani, M., Champollion, C., Di Iorio, T., Engelmann, R., Herold, C., Pal, S., Riede, A., Wirth, M., and Wulfmeyer, V.: The Water Vapour Intercomparison Effort in the Framework of the Convective and Orographically-Induced Precipitation Study: Air-borne-toGround-based and airborne-to-airborne Lidar Systems, Q. J. Roy. Meteor. Soc., 137, 325-348, 2011.

Blumberg, W. G., Turner, D. D., Löhnert, U., and Castleberry, S.: Ground-Based Temperature and Humidity Profiling Using Spectral Infrared and Microwave Observations - Part II: Actual Retrieval Performance in Clear-Sky and Cloudy Conditions, J. Appl. Meteor. Climatol., 54, 2305-2319, doi:10.1175/JAMC-D15-0005.1, 2015.

Bösenberg, J.: Ground-based differential absorption lidar for watervapor and temperature profiling: methodology, Appl. Opt., 37, 3845-3860, 1998.

Browell, E. V., Wilkerson, T. D., and McIlrath, T. J.: Water vapor differential absorption lidar development and evaluation, Appl. Opt., 18, 3474-3483, 1979.

Bruneau, D., Quaglia, P., Flamment, C., Meissonnier, M., and Pelon, J.: Airborne lidar LEANDRE II for water-vapor profiling in the troposphere, I. System description, App. Opt., 40, 34503461, doi:10.1364/AO.40.003450, 2001.

Brutsaert, W.: Evaporation into the Atmosphere, Kluwer Academic Publishers, Dordrecht, the Netherlands, 1982.

Cohen, A. E., Cavallo, S. M., Coniglio, M. C., and Brooks, H. E.: A Review of Planetary Boundary Layer Parameterization Schemes and Their Sensitivity in Simulating Southeastern U.S. Cold Season Severe Weather, Weather Forecast., 30, 591-612, doi:10.1175/WAF-D-14-00105.1, 2015.

Corsmeier, U., Kalthoff, N., Barthlott, C., Aoshima, F., Behrendt, A., Di Girolamo, P., Dorninger, M., Handwerker, J., Kottmeier, C., Mahlke, H., Mobbs, S. D., Norton, E. G., Wickert, J., and Wulfmeyer, V.: Processes driving deep convetion over complex terrain: a multi-scale analysis of observations from COPS IOP 9b, Q. J. Roy. Meteor. Soc., 137, 137-155, doi:10.1002/qj.754, 2011.

Crook, N. A.: Sensitivity of moist convection forced by boundary layer processes to low-level thermodynamic fields, Mon Weather Rev., 124, 1767-1785, 1996.

Dierer, S., Arpagaus, M., Seifert, A., Avgoustoglou, E., Dumitrache, R., Grazzini, F., Mercogliano, P., Milelli, M., and Starosta, K.: Deficiencies in quantitative precipitation forecasts: Sensitivity studies using the COSMO model, Meteorol. Z., 18, 631-645, doi:10.1127/0941-2948/2009/0420, 2009. 
Ehret, G., Kiemle, C., Wirth, M., Stoffelen, A., Kummer, U., Schulte, H. R., et al.: Evaluation of spaceborne differential absorption lidar for water vapour, Final Report, ESA Study 3654/00/NL/DC, 2001.

Eichinger, W., Cooper, D., Froman, P. R., Griegos, J., Osborn, M. A. M., Richter, D., Tellier, L. L., and Thronton, R.: The Development of a Scanning Raman Water Vapor Lidar for Boundary Layer and Tropospheric Observations, J. Atmos. Oceanic Technol., 16, 1753-1766, doi:10.1175/15200426(1999)016<1753:TDOASR>2.0.CO;2, 1999.

Eichinger, W., Cooper, D., Kao, J., Chen, L.C., Hipps, L., and Prueger, J.: Estimation of spatially distributed latent heat flux over complex terrain from a Raman lidar, Agr. Forest Meteorol., 105, 145-159, doi:10.1016/s0168-1923(00)00183-0, 2000.

Ek, M. B., Mitchell, K. E., Y. Lin, Y., Rogers, E., Grunmann, P., Koren, V., Gayno, G., and Tarpley, J. D.: Implementation of Noah land surface model advances in the National Centres for Environmental Prediction operational mesoscale Eta model, J. Geophys. Res., 108, 8851, doi:10.1029/2002JD003296, 2003.

Ertel, K.: Application and Development of Water Vapor DIAL Systems, Doctoral Thesis, University of Hamburg, Germany, 2004.

Fernald, F. G.: Analysis of the atmospheric lidar observations: some comments, Appl. Opt., 23, 652-653, 1984.

Fernald, F. G., Herman, B. M., and Reagan, J. A.: Determination of Aerosol height Distributions by Lidar, J. Appl. Meteorol., 11, 482-489, 1972.

Findell, K. L. and Eltahir, E. A. B.: Atmospheric Controls on Soil Moisture-Boundary Layer Interactions - Part II: Feedbacks within the Continental United States, J. Hydrometeor, 4, 570-583, doi:10.1175/15257541(2003)004<0570:ACOSML>2.0.CO;2, 2003.

Fix, A., Ehret, G., Löhring, J., Hoffmann, D., and Alpers, M.: Water vapor differential absorption lidar measurements using a diodepumped all-solid-state laser at $935 \mathrm{~nm}$, App. Phys. B, 102, 905915, doi:10.1007/s00340-010-4310-5, 2011.

Froidevaux, M., Higgins, C. W., Simeonov, V., Ristori, P., Pardyjak, E., Serikov, I., Calhoun, R., van den Bergh, H., and Parlange, M. B.: A Raman lidar to measure water vapor in the atmospheric boundary layer, Adv. Water Resour., 51, 345-356, doi:10.1016/j.advwatres.2012.04.008, 2013.

Goldsmith, J. E. M., Blair, F. H., Bisson, S. E., and Turner, D. D.: Turn-key Raman lidar for profiling atmospheric water vapor, clouds, and aerosols, Appl. Opt., 37, 4979-4990, doi:10.1364/AO.37.004979, 1998.

Hammann, E., Behrendt, A., Le Mounier, F., and Wulfmeyer, V.: Temperature profiling of the atmospheric boundary layer with rotational Raman lidar during the $\operatorname{HD}(\mathrm{CP})^{2}$ Observational Prototype Experiment, Atmos. Chem. Phys., 15, 2867-2881, doi:10.5194/acp-15-2867-2015, 2015.

Hong, S.-Y.: Stable Boundary Layer Mixing in a Vertical Diffusion Scheme, the Korea Meteor. Soc., Fall conference, Seoul, Korea, 25-26 October, 2007.

Hong, S.-Y., Noh, Y., and Dudhia, J.: A New Vertical Diffusion Package with an Explicit Treatment of Entrainment Processes, Mon. Weather Rev., 134, 2318-2341, doi:10.1175/MWR3199.1, 2006.

Ismail, S. and Browell, E. V.: Airborne and spaceborne lidar measurements of water vapor profiles: a sensitivity analysis, Appl. Opt., 28, 3603-3615, 1989.
Kalthoff, N., Fiebig-Wittmaack, M., Meißner, C., Kohler, M., Uriarte, M., Bischoff-Gauß, I., and Gonzales, E.: The energy balance, evapo-transpiration and nocturnal dew deposition of an arid valley in the Andes, J. Arid Environ., 65, 420-443, 2006.

Kalthoff, N., Adler, B., Wieser, A., Kohler, M., Träumner, K., Handwerker, J., Corsmeier, U., Khodayar, S., Lambert, D., Kopmann, A., Kunka, N., Dick, G., Ramatschi, M., Wickert, J., and Kottmeier, C.: KITcube - a mobile observation platform for convection studies deployed during HyMeX, Meteorol. Z., 22, 633647, 2013.

Koster, R. D., Sud, Y. C., Guo, Z., Dirmeyer, P. A., Bonan, G., Oleson, K. W., Chan, E., Verseghy, D., Cox, P., Davies, H., Kowalczyk, E., Gordon, C. T., Kanae, S., Lawrence, D., Liu, P., Mocko, D., Lu, C.-H., Mitchell, K., Malyshev, S., McAvaney, B., Oki, T., Yamada, T., Pitman, A., Taylor, C. M., Vasic, R., and Xue, Y.: GLACE: The Global Land-Atmosphere Coupling Experiment - Part I: Overview, J. Hydrometeor, 7, 590-610, doi:10.1175/JHM510.1, 2006.

Kotlarski, S., Keuler, K., Christensen, O. B., Colette, A., Déqué, M., Gobiet, A., Goergen, K., Jacob, D., Lüthi, D., van Meijgaard, E., Nikulin, G., Schär, C., Teichmann, C., Vautard, R., Warrach-Sagi, K., and Wulfmeyer, V.: Regional climate modeling on European scales: a joint standard evaluation of the EUROCORDEX RCM ensemble, Geosci. Model Dev., 7, 1297-1333, doi:10.5194/gmd-7-1297-2014, 2014.

Krauss, L., Hauck, C., and Kottmeier, C.: Spatio-temporal soil moisture variability in Southwest Germany observed with a new monitoring network within the COPS domain, Meteorol. Z., 19, 523-537, 2010.

Lenschow, D. H., Wulfmeyer, V., and Senff, C.: Measuring secondthrough fourth-order moments in noisy data, J. Atmos. Oceanic. Tech., 17, 1330-1347, 2000.

Löhnert, U., Turner, D. D., and Crewell, S.: Ground-based temperature and humidity profiling using spectral infrared and microwave observations - Part I: Simulated retrieval performance in clear-sky conditions, J. Appl. Meteorol. Climatol., 48, 10171032, doi:10.1175/2008JAMC2060.1, 2009.

Machol, J. L., Ayers, T., Schwenz, K. T., Koenig, K. W., Hardesty, R. M., Senff, C. J., Krainak, M. A., Abshire, J. B., Bravo, H. E., and Sandberg, S. P.: Preliminary Measurements with an Automated Compact Differential Absorption Lidar for the Profiling of Water Vapor, Appl. Opt., 43, 3110-3121, doi:10.1364/AO.43.003110, 2004.

Machol, J. L., Ayers, T., Schwenz, K. T., Koenig, K. W., Hardesty, R. M., Senff, C. J., Krainak, M. A., Abshire, J. B., Bravo, H. E., and Sandberg, S. P.: Preliminary measurements with an automated compact differential absorption lidar for the profiling of water vapor: errata, Appl. Opt., 45, 3544, doi:10.1364/AO.45.003544, 2006.

Matsuda, M.: Development of a scanning Raman lidar for observing the spatio-temporal distribution of water vapor, Master Thesis, Bulletin of Research Institute for Sustainable Humanosphere Kyoto University, Japan, 9, 42-42, 2013.

Melfi, S. H., Lawrence, J. D., and McCormick, M. P.: Observation of Raman scattering by water vapor in the atmosphere, Appl. Phys. Lett., 15, 295-297, 1969.

Mellor, G. L. and Yamada, T.: Development of a turbulence closure model for geophysical fluid problems, Rev. Geophys. Space Phys., 20, 851-875, doi:10.1029/RG020i004p00851, 1982. 
Metzendorf, S., Behrendt, A., Späth, F., and Wulfmeyer, V.: HighPower Laser Transmitter of the UHOH Water Vapor DIAL, in: 26th International Laser Radar Conference (ILRC 2012), Porto Heli, Greece, 25-29 June 2012, 117-120, 2012.

Metzendorf, S., Wulfmeyer, V., Behrendt, A., Späth, F., and Riede, A.: Frequency-Agile Ti:Sapphire Laser System with High Power and High Pulse Energy for Spectroscopic Applications, Conference on Lasers and Electro-Optics (CLEO/Europe), Munich, Germany, 21-25 June 2015, CA-12.5, 2015.

Milovac, J., Warrach-Sagi, K., Behrendt, A., Späth, F., Ingwersen, J., and Wulfmeyer, V.: Investigation of PBL schemes combining the WRF model simulations with scanning water vapor DIAL measurements, J. Geophys. Res. Atmos., 121, 624-649, doi:10.1002/2015JD023927, 2016.

Monin, A. S. and Obukhov, A. M.: Basic laws of turbulent mixing in the surface layer of the atmosphere, Tr. Akad. Nauk SSSR Geophiz. Inst., 24, 163-187, 1954.

Muppa, S. K., Behrendt, A., Späth, F., Wulfmeyer, V., Metzendorf, S., and Riede, A.: Turbulent humidity fluctuations in the convective boundary layer: Case studies using DIAL measurements, Bound.-Lay. Meteorol., 158, 43-66, doi:10.1007/s10546015-0078-9, 2016.

Nakanishi, M. and Niino, H.: Development of an Improved Turbulence Closure Model for the Atmospheric Boundary Layer, J. Meteorol. Soc. Jpn., 87, 895-912, doi:10.2151/jmsj.87.895, 2009.

NASA (National Aeronautics and Space Administration): US Standard Atmosphere, US Government Printing Office, Washington, DC, 1976

Niu, G.-Y., Yang, Z.-L., Mitchell, K. E., Chen, F., Ek, M. B., Barlage, M., Kumar, A., Manning, K., Niyogy, D., Rosero, E., Tewari, M., and Xia, Y.: The community Noah land surface model with multiparameterization options (Noah-MP): 1. Model description and evaluation with local-scale measurements, J. Geophys. Res., 116, D12109, doi:10.1029/2010JD015139, 2011.

Ostermeyer M., Kappe P., Menzel R., and Wulfmeyer V.: Diodepumped Nd:YAG master oscillator power amplifier with high pulse energy, excellent beam quality, and frequency-stabilized master oscillator as a basic for a next-generation lidar system, App. Opt., 44, 582-590, doi:10.1364/AO.44.000582, 2005.

Petrova-Mayor, A., Wulfmeyer, V., and Weibring, P.: Development of an eye-safe solid-state tunable laser transmitter in the 1.4-1.5$\mu \mathrm{m}$ wavelength region based on $\mathrm{Cr} 4+$ :YAG crystal for lidar applications, Appl. Opt., 47, 1522-1534, 2008.

Radlach, M., Behrendt, A., and Wulfmeyer, V.: Scanning rotational Raman lidar at $355 \mathrm{~nm}$ for the measurement of tropospheric temperature fields, Atmos. Chem. Phys., 8, 159-169, doi:10.5194/acp-8-159-2008, 2008.

Riede, A., Behrendt, A., Wulfmeyer, V., Althausen, D., Wandinger, U., Klein, V., Meister, A., and Schiller, M.: Transmitter-Receiver Unit of the UHOH Water Vapor DIAL with a Scanning 800$\mathrm{mm}$ Telescope Mirror, 26th International Laser Radar Conference (ILRC 2012), Porto Heli, Greece, 25-29 June 2012, 121124, 2012.

Rothman, L. S., Gordon, I. E., Babikov, Y., Barbe, A., Chris Benner, D., Bernath, P. F., Birk, M., Bizzocchi, L., Boudon, V., Brown, L. R., Campargue, A., Chance, K., Cohen, E. A., Coudert, L. H., Devi, V. M., Drouin, B. J., Fayt, A., Flaud, J.-M., Gamache, R. R., Harrison, J. J., Hartmann, J.-M., Hill, C., Hodges, J. T.,
Jacquemart, D., Jolly, A., Lamouroux, J., Le Roy, R. J., Li, G., Long, D. A., Lyulin, O. M., Mackie, C. J., Massie, S. T., Mikhailenko, S., Müller, H. S. P., Naumenko, O. V., Nikitin, A. V., Orphal, J., Perevalov, V., Perrin, A., Polovtseva, E. R., Richard, C., Smith, M. A. H., Starikova, E., Sung, K., Tashkun, S., Tennyson, J., Toon, G. C., Tyuterev, V. I. G., and Wagner, G.: The HITRAN 2012 Molecular Spectroscopic Database, J Quant. Spectrosc. Ra., 130, 4-50, 2013.

Santanello, J. A., Peters-Lidard, C. D., Kennedy, A., and Kumar, S. V.: Diagnosing the Nature of Land-Atmosphere Coupling: A Case Study of Dry/Wet Extremes in the U.S. Southern Great Plains, J. Hydrometeor., 14, 3-24, doi:10.1175/JHMD-12-023.1, 2013.

Savitzky, A. and Golay, M. J. E.: Smoothing and Differentiation of Data by Simplified Least Squares Procedures, Anal. Chem., 36, 1627-1639, doi:10.1021/ac60214a047, 1964.

Schiller, M.: A high-power laser transmitter for ground-based and airborne water-vapor measurements in the troposphere, Doctoral Thesis, University of Hohenheim, Germany, 2009.

Schotland, R. M.: Some Observations of the Vertical Profile of Water Vapor by Means of a Ground Based Optical Radar, 4th Symposium on Remote Sensing of Environment, U. Michigan, Ann Arbor, 12-24 April, 1966.

Schotland, R. M.: Errors in the Lidar Measurement of Atmospheric Gases by Differential Absorption, J. Appl. Meteorol., 13, 71-77, 1974.

Schiller, M., Wulfmeyer, V., Riede, A., Behrendt, A., Bauer, H., Wagner, G., Wandinger, U., and Althausen, D.: Scanning Water Vapor DIAL Based on a High-Power Ti:Sapphire Laser: First Experimental Results, Lidar Technologies, Techniques, and Measurements for Atmospheric Remote Sensing, SPIE International Symposium on Remote Sensing, Florence, Italy, 17-21 September, 2007.

Shin, H. H. and Hong, S.-Y.: Intercomparison of Planetary Boundary-Layer Parameterizations in the WRF Model for a Single Day from CASES-99, Bound. Lay. Meteorol., 139, 261-281, doi:10.1007/s10546-010-9583-z, 2011.

Seneviratne, S. I., Corti, T., Davin, E. L., Hirschi, M., Jaeger, E. B., Lehner, I., Orlowski, B., and Teuling, A. J.: Investigating soil moisture-climate interactions in a changing climate: A review, Earth Sci. Rev., 99, 125-161, doi:10.1016/j.earscirev.2010.02.004, 2010.

Shin, H. H. and Hong, S.-Y.: Representation of the SubgridScale Turbulent Transport in Convective Boundary Layers at Gray-Zone Resolutions, Mon. Weather Rev., 143, 250-271, doi:10.1175/MWR-D-14-00116.1, 2015.

Späth, F., Metzendorf, S., Behrendt, A., Wizemann, H. D., Wagner, G., and Wulfmeyer, V.: Online/Offline injection seeding system with high frequency-stability and low crosstalk for water vapor DIAL, Opt. Commun., 309, 37-43, doi:10.1016/j.optcom.2013.07.003, 2013.

Späth, F., Behrendt, A., Muppa, S. K., Metzendorf, S., Riede, A., and Wulfmeyer, V.: High-resolution atmospheric water vapor measurements with a scanning differential absorption lidar, Atmos. Chem. Phys. Discuss., 14, 29057-29099, doi:10.5194/acpd-14-29057-2014, 2014.

Späth, F., Behrendt, A., and Wulfmeyer, V.: Sensitivity of the Rayleigh-Doppler effect with respect to wavelength and 
backscatter coefficient, 27th International Laser Radar Conference (ILRC 2015), New York, USA, 5-10 July, 2015.

Spuler, S. M., Repasky, K. S., Morley, B., Moen, D., Hayman, M., and Nehrir, A. R.: Field-deployable diode-laser-based differential absorption lidar (DIAL) for profiling water vapor, Atmos. Meas. Tech., 8, 1073-1087, doi:10.5194/amt-8-1073-2015, 2015.

Steinke, S., Löhnert, U., Crewell, S., and Liu, S.: Water vapor tomography with two microwave radiometers, IEEE Geosci. Remote Sens. Lett., 11, 419-423, doi:10.1109/LGRS.2013.2264354, 2014.

Träumner, K.: Einmischprozesse am Oberrand der konvektiven atmosphärischen Grenzschicht, Doctoral Thesis, Karlsruhe Institute of Technology, Germany, 2010.

Turner, D. D., Ferrare, R. A., Heilman Brasseur, L. A., Feltz, W. F., and Tooman, T. P.: Automated Retrievals of Wate Vapor and Aerosol Profiles from an Operational Raman Lidar., J. Atmos. Oceanic Technol., 19, 37-50, doi:10.1175/15200426(2002)019<0037:AROWVA>2.0.CO;2, 2002.

van Heerwaarden, C. C., Vilà-Guerau de Arellano, J., Moene, A. F., and Holtslag, A. A. M.: Interactions between dryair entrainment, surface evaporation and convective boundarylayer development, Q. J. Roy. Meteor. Soc., 135, 1277-1291, doi:10.1002/qj.431, 2009.

Vogelmann, H. and Trickl, T.: Wide Range Sounding of Free Tropospheric Water Vapor with a Differential Absorption Lidar (DIAL) at a High Altitude Station, Appl. Opt., 47, 2116-2132, doi:10.1364/AO.47.002116, 2008.

Wagner, G., Wulfmeyer, V., and Behrendt, A.: Detailed performance modeling of a pulsed high-power single-frequency Ti:sapphire laser, Appl. Opt., 50, 5921-5937, 2011.

Wagner, G., Behrendt, A., Wulfmeyer, V., Späth, F., and Schiller, M.: High-power Ti:sapphire laser at $820 \mathrm{~nm}$ for scanning groundbased water-vapor differential absorption lidar, Appl. Opt., 52, 2454-2469, 2013.

Warrach-Sagi, K., Schwitalla, T., Wulfmeyer, V., and Bauer, H. S.: Evaluation of a climate simulation based on the WRF-NOAH model system: Precipitation in Germany, Clim. Dynam., 41, 755-774, doi:10.1007/s00382-013-1727-7, 2013.

Whiteman, D. N., Melfi, S. H., and Ferrare, R. A.: Raman lidar system for the measurement of water vapor and aerosols in the Earth's atmosphere, Appl. Opt., 31, 3068-3082, 1992.

Whiteman, D. N., Demoz, B., Rush, K., Schwemmer, G., Gentry, B., Di Girolamo, P., Comer, J., Veselovskii, I., Evans, K., Melfi, S. H., Wang, Z., Cadirola, M., Mielke, B., Venable, D., and Van Hove, T.: Raman Lidar Measurements during the International $\mathrm{H}_{2} \mathrm{O}$ Project - Part I: Instrumentation and Analysis Techniques, J. Atmos. Oceanic Technol., 23, 157-169, doi:10.1175/JTECH1838.1, 2006.

Wirth, M., Fix, A., Mahnke, P., Schwarzer, H., Schrandt, F., and Ehret, G.: The airborne multi-wavelength water vapor differential absorption lidar WALES: System design and performance, Appl. Phys. B, 96, 201-213, doi:10.1007/s00340-009-3365-7, 2009

Wizemann, H. D., Ingwersen, J., Högy, P., Warrach-Sagi, K., Streck, T., and Wulfmeyer, V.: Three year observations of water vapor and energy fluxes over agricultural crops in two regional climates of Southwest, Germany, Meteorol. Z., 24, 39-59, doi:10.1127/metz/2014/0618, 2015.
Wulfmeyer, V. and Bösenberg, J.: Single-mode operation of an injection-seeded alexandrite ring laser for application in watervapor and temperature differential absorption lidar, Opt. Lett., 21, 1150-1152, doi:10.1364/OL.21.001150, 1996.

Wulfmeyer, V. and Bösenberg, J.: Ground-based differential absorption lidar for water-vapor profiling: Assessment of accuracy, resolution, and meteorological applications, Appl. Opt. 37, 38253844, doi:10.1364/AO.37.003825, 1998.

Wulfmeyer, V., Randall, M., Brewer, A., and Hardesty, R. M.: 2- $\mu \mathrm{m}$ Doppler lidar transmitter with high frequency stability and low chirp, Opt. Lett., 25, 1228-1230, 2000.

Wulfmeyer, V. and Walther, C.: Future performance of groundbased and airborne water-vapor differential absorption lidar - I: Overview and Theory, Appl. Opt., 40, 5304-5320, $2001 \mathrm{a}$.

Wulfmeyer, V. and Walther, C.: Future performance of groundbased and airborne water-vapor differential absorption lidar - II: Simulations of the precision of a near-infrared, high power system, Appl. Opt., 40, 5321-5336, $2001 \mathrm{~b}$.

Wulfmeyer, V., Turner, D. D., Pal, S., and Wagner, E.: Can Water Vapour Raman Lidar Resolve Profiles of Turbulent Variables in the Convective Boundary Layer?, Bound.-Lay. Meteorol., 136, 253-284, doi:10.1007/s10546-010-9494-z, 2010.

Wulfmeyer, V., Behrendt, A., Kottmeier, C., Corsmeier, U., Barthlott, C., Craig, G. C., Hagen, M., Althausen, D., Aoshima, F., Arpagaus, M., Bauer, H. S., Bennett, L., Blyth, A., Brandau, C., Champollion, C., Crewell, S., Dick, G., Di Girolamo, P., Dorninger, M., Dufournet, Y., Eigenmann, R., Engelmann, R., Flamant, C., Foken, T., Gorgas, T., Grzeschik, M., Handwerker, J., Hauck, C., Höller, H., Junkermann, W., Kalthoff, N., Kiemle, C., Klink, S., König, M., Krauss, L., Long, C. N., Madonna, F., Mobbs, S., Neininger, B., Pal, S., Peters, G., Pigeon, G., Richard, E., Rotach, M. W., Russchenberg, H., Schwitalla, T., Smith, V., Steinacker, R., Trentmann, J., Turner, D. D., van Baelen, J., Vogt, S., Volkert, H., Weckwerth, T., Wernli, H., Wieser, A., and Wirth, M.: The Convective and Orographically Induced Precipitation Study (COPS): The Scientific Strategy, the Field Phase, and First Highlights, Q. J. Roy. Meteor. Soc., 137, 3-30, doi:10.1002/qj.752, 2011.

Wulfmeyer, V., Warrach-Sagi, K., Schwitalla, T., Bauer, H. S., and Milovac, J.: Towards seamless mesoscale prediction of the land system for Europe, The World Weather Open Science Conference, Montreal, Canada, 16-21 August, 2014.

Wulfmeyer, V., Hardesty, R. M., Turner, D. D., Behrendt, A., Cadeddu, M. P., Di Girolamo, P., Schüssel, P., Van Baelen, J., and Zus, F.: A review of remote sensing of lower tropospheric thermodynamic profiles and its indispensable role for the understanding and simulation of water and energy cycles, Rev. Geophys., 53, 819-895, doi:10.1002/2014RG000476, 2015.

Wulfmeyer, V., Muppa, S. K., Behrendt, A., Hammann, E., Späth, F., Sorbjan, Z., Turner, D. D., and Hardesty, R. M.: Determination of Convective Boundary Layer Entrainment Fluxes, Dissipation Rates, and the Molecular Destruction of Variances: Theoretical Description and a Strategy for its Confirmation with a Novel Lidar System Synergy, J. Atmos. Sci., 73, 667-692, doi:10.1175/JAS-D-14-0392.1, 2016. 